\title{
WestVirginiaUniversity
}

THE RESEARCH REPOSITORY @ WVU

Graduate Theses, Dissertations, and Problem Reports

2018

\section{Assessment of Tapered Diamond Bur Cutting Efficiency of Dental Zirconia}

Dhari Alenezi

Follow this and additional works at: https://researchrepository.wvu.edu/etd

\section{Recommended Citation}

Alenezi, Dhari, "Assessment of Tapered Diamond Bur Cutting Efficiency of Dental Zirconia" (2018). Graduate Theses, Dissertations, and Problem Reports. 5056.

https://researchrepository.wvu.edu/etd/5056

This Thesis is protected by copyright and/or related rights. It has been brought to you by the The Research Repository @ WVU with permission from the rights-holder(s). You are free to use this Thesis in any way that is permitted by the copyright and related rights legislation that applies to your use. For other uses you must obtain permission from the rights-holder(s) directly, unless additional rights are indicated by a Creative Commons license in the record and/ or on the work itself. This Thesis has been accepted for inclusion in WVU Graduate Theses, Dissertations, and Problem Reports collection by an authorized administrator of The Research Repository @ WVU. For more information, please contact researchrepository@mail.wvu.edu. 
Assessment of Tapered Diamond Bur Cutting Efficiency of Dental Zirconia

Dhari Alenezi, D.D.S.

Thesis submitted to the

School of Dentistry

At West Virginia University

In Partial fulfillment of the requirements

For the degree of

Master of Science

In

Prosthodontics

\author{
Matthew S Bryington D.M.D., M.S. (Chair) \\ Bryan D. Dye, D.D.S., M.S. \\ Elizabeth Kao, D.M.D.
}

Department of Restorative Dentistry

Morgantown, West Virginia

2018

Keywords: Diamond bur cutting efficiency, 3Y-TZP, Dental Zirconia, crown removal

Copyright 2018 Dhari Alenezi 


\begin{abstract}
Assessment of Tapered Diamond Bur Cutting Efficiency of Dental Zirconia

Dhari Alenezi, D.D.S.
\end{abstract}

Objectives: To evaluate the cutting efficiency, measured by rate, of tapered diamond burs with different grit sizes on sintered yttrium stabilized zirconia.

Methods: Seven types of tapered diamond burs with different grit sizes and with a 1.4 $\mathrm{mm}$ diameter were tested against sintered Yttrium stabilized zirconia blocks using an airturbine handpiece and $0.9 \mathrm{~N}$ of cutting force. The burs utilized were: super coarse 181 $\mu \mathrm{m}$, super coarse $150 \mu \mathrm{m}$, coarse $151 \mu \mathrm{m}$, coarse $125 \mu \mathrm{m}$, medium $107 \mu \mathrm{m}$, medium 100 $\mu \mathrm{m}$ and DuraCut $151 \mu \mathrm{m}$. Ten samples of each bur type were used. Depth of the cuts was measured by a Linear Variable Differential Transformer (LVDT) and data acquisition device. Each test was run for 5 minutes and divided into 3 time periods of 100 seconds each. A mixed-effect ANOVA test was completed for the effect of burs, time periods and combined effect of bur and time periods. A Tukey-Kramer HSD test was completed. Results of the study were compared to a previous study with parallel sided diamond burs using one-way ANOVA for the similar burs. P values were calculated to show significant differences.

Results: A significant difference was found among the burs and among time periods on cutting efficiency of 3Y-TZP. Coarse $151 \mu \mathrm{m}$ super coarse $181 \mu \mathrm{m}$ and DuraCut $151 \mu \mathrm{m}$ were significantly more efficient in cutting $3 \mathrm{Y}$-TZP in 5 minutes and in the first 100 seconds. Diamond burs with average grit size $\geq 151$ demonstrated greater cutting efficiency. Within 5 minutes, the most efficient burs, coarse $151 \mu \mathrm{m}$, super coarse 181 and DuraCut $151 \mu \mathrm{m}$, had cutting depths of 4.35, 3.96 and $3.90 \mathrm{~mm}$ respectively. The cutting efficiency during the first 100 seconds was significantly greater for all burs. Comparison between tapered burs from this study and parallel burs from another study showed no significant difference in cutting efficiency between parallel sided and tapered shape diamond burs in cutting efficiency of diamond burs.

Conclusions: Diamond burs with an average grit size $(\geq 151 \mu \mathrm{m})$ were the most efficient burs for cutting sintered 3Y-TZP within 5 minutes and in the first 100 seconds.

Manufacturing process apparently plays an important role in improving cutting efficiency of diamond burs. All of the burs showed a significant decrease in cutting efficiency after 100 seconds. No difference was found between tapered diamond burs and parallel side burs. Cutting efficiency of diamond burs on 3Y-TZP is partially dependent on the coarseness of the bur. 


\section{DEDICATION}

I would like to dedicate this paper to my wonderful wife, Afrah, who has provided a huge support during my residency. Without you in my life, I would have not completed my specialty training. Your affection and your faith in me will always be my driving power toward success. 


\section{ACKNOWLEGEMENTS}

I would like to thank the following for their role in my post-doctoral training and education:

Dr. Matthew S. Bryington, Thank you for all the training that you have sincerely provided through my prosthodontic training and for all the support you have given through the past three years.

Dr. Bryan D. Dye, Thank you so much for all your involvement in my dental and my post graduate training that I am very proud of.

Dr. Elizabeth Kao, You have showed so much support since the beginning of my dental school education. I am honored to have you participate in my post-graduate training as well. Thanks for all the support and education you have provided.

Dr. Gerald Hobbs, Thank you for the statistical work. Without you, this project would have not been completed.

Also, I'd like to thank the following for their donation of the materials for the project:

Todd Warner and Ivoclar Vivadent for providing the sintered zirconia blocks.

Joe Rittler and Brasseler USA for providing the Brasseler burs. 


\section{TABLE OF CONTENTS}

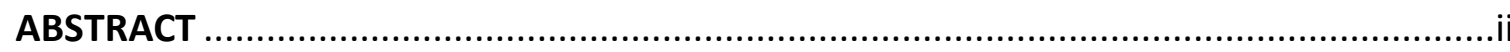

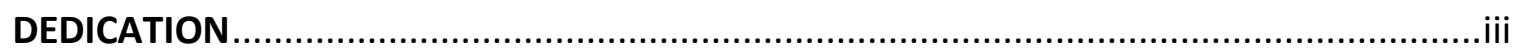

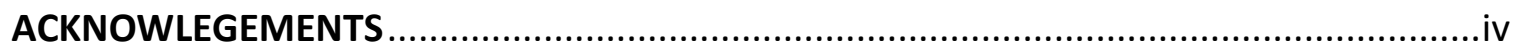

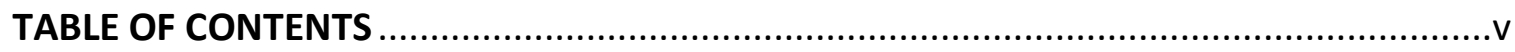

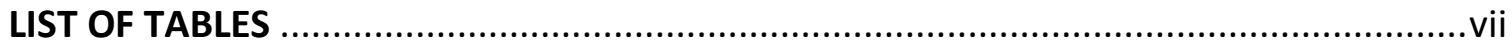

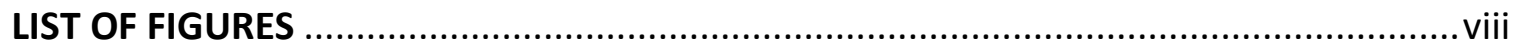

LIST OF SYMBOLS, ABBREVIATIONS OR NOMELCLATURE ...........................................ix

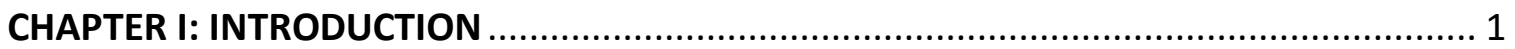

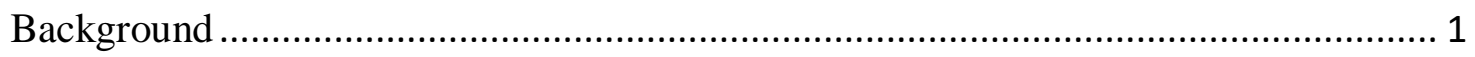

Statement of the Problem..................................................................................... 2

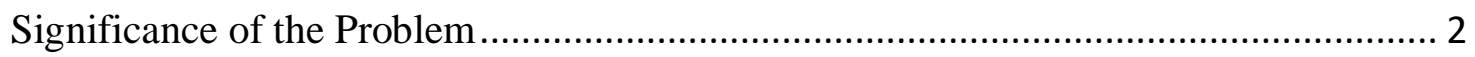

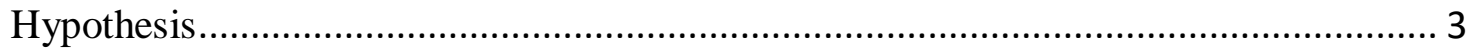

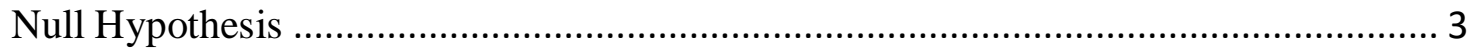

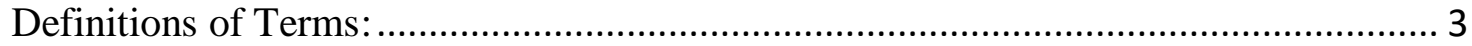

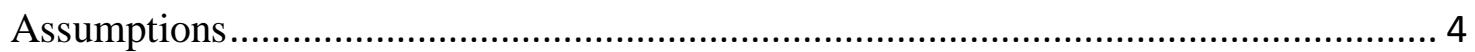

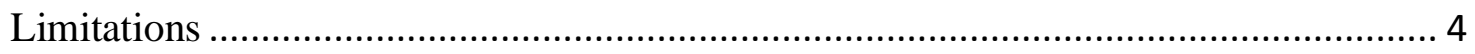

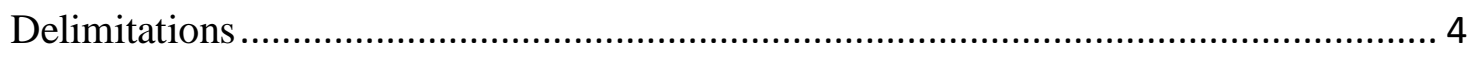

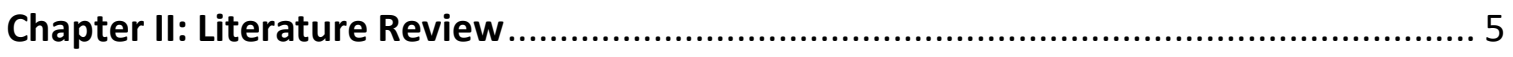

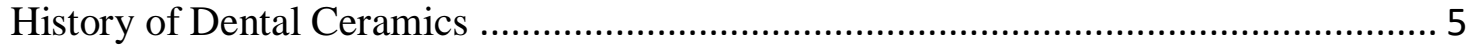

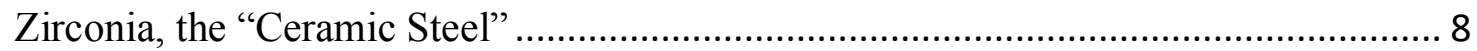

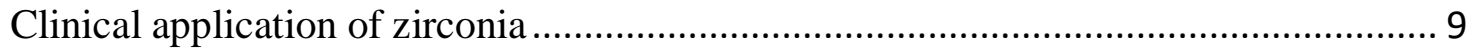

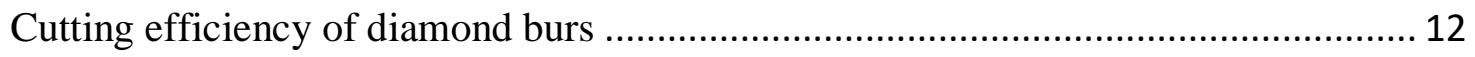

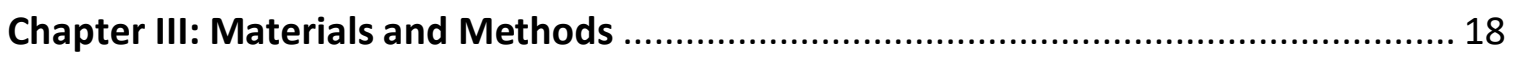

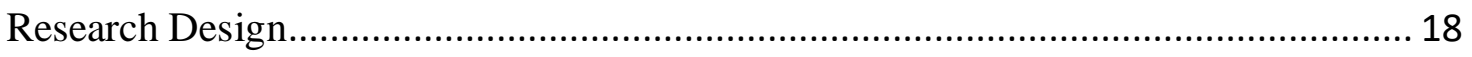

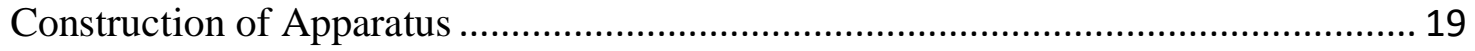

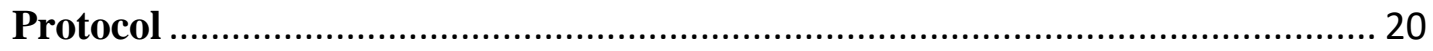

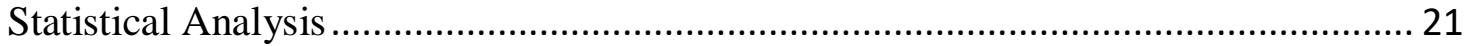

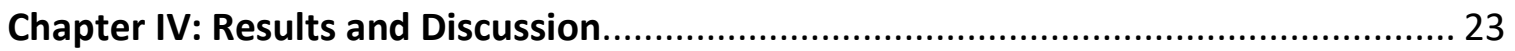




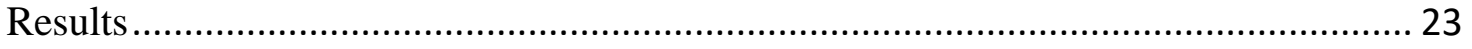

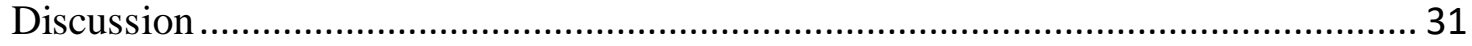

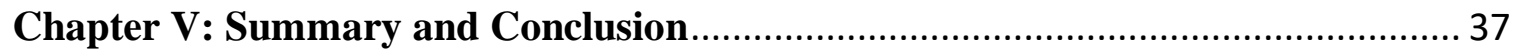

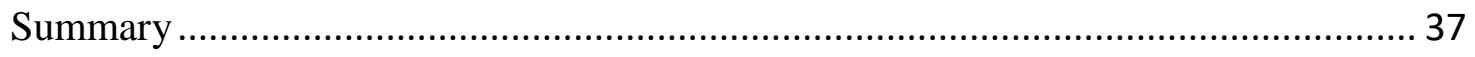

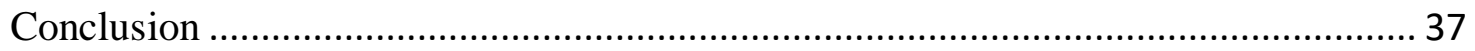

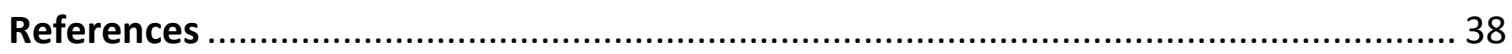

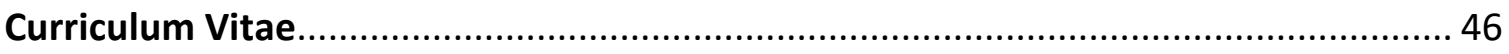




\section{LIST OF TABLES}

Table 1: Tapered diamond burs used in the experiment

Table 2: Selected tapered burs and the corresponding parallel burs from a previous study.

Table 3: Mixed Effects ANOVA.

Table 4: Tukey-Kramer HSD defining significance between burs through the 5 minutes

Table 5: Tukey-Kramer HSD defining significance between periods.

Table 6: Tukey-Kramer HSD defining differences between burs in Period 1.

Table 7: Analysis of variance between tapered and parallel shaped burs. 


\section{LIST OF FIGURES}

Figure 1: The setup of the experiment.

Figure 2: Experiment apparatus.

Figure 3: The zirconia specimen mounted on the platform.

Figure 4: Averaged cutting efficiency of test burs over 5 minutes.

Figure 5: Averaged distance cut of each bur group after 5 minutes.

Figure 6: Cutting efficiency average for bur groups in each Period.

Figure 7: A comparison of the Average distance traveled by each bur in 5 minutes between tapered burs and parallel burs. 


\section{LIST OF SYMBOLS, ABBREVIATIONS OR NOMELCLATURE}

CAD-CAM: Computer Aided Design and Computer Aided Manufacturing

PFM: Porcelain Fused to Metal

3Y-TZP: Yttrium stabilized Tetragonal Zirconia Polycrystal

CTE: Coefficient of Thermal Expansion

ZTA: Zirconia Toughened Alumina

PSZ: Partially Stabilized Zirconia

TZP: Tetragonal Zirconia Polycrystal

LVDT: Linear Variable Differential Transformer

LTD: Low Temperature Degradation

SEM: Scanning Electron Microscope

Er:YAG: Erbium-doped Yttrium Aluminium Garnet laser 


\section{CHAPTER I: INTRODUCTION}

\section{Background}

Single crown restorations and fixed dental prostheses have a long history of success and failure that have expanded the treatment modalities we offer to patients. Clinicians have always tried to find an ideal material for tooth restoration that meets the patient's esthetic and functional needs. However, there has always been a compromise between esthetics and strength, as the esthetic materials are usually weak while stronger materials do not meet the patient's increasingly high esthetic expectations. ${ }^{1}$ Variable materials with different degrees of esthetics and strength have been introduced in clinical dentistry as a result of advancement in ceramic engineering technology.

Strong ceramic restorative materials have been accurately designed and manufactured with the improvement of the Computer Aided Design and Computer Aided Manufacturing (CAD-CAM). ${ }^{2}$ Dental applications of CAD-CAM technology started in early 1980s and allowed technicians and dentists to use higher quality ceramics. The technology records surface coordinates of a prepared surface into the computer where a design of the prosthesis can be made. A milling procedure of the proposed design starts later with good accuracy and minimal porosity. ${ }^{3}$ Advancements in this new technology made processing strong ceramics into a complex shape such as a restoration a viable and predictable option. ${ }^{2}$ All-ceramic restorations became a popular treatment option in dentistry. ${ }^{4}$ With the increase advances of such restorations, patient esthetic expectations have also been increasing. ${ }^{5}$

Yttrium stabilized tetragonal zirconia polycrystal (3Y-TZP) is a strong ceramic material that has been used for anterior and posterior regions. Due to its high strength and relatively adequate optical properties, more attention was brought toward zirconia restorations as an alternative for porcelain fused to metal restorations. ${ }^{6}$ Zirconia has been used as a core material to 
provide strength to layered porcelain veneer or as a monolithic restoration. ${ }^{7}$ It showed acceptable treatment outcome that were comparable to porcelain fused to metals restorations. ${ }^{8}$

As any other dental material, zirconia restorations are not immune to failures, necessitating the need for replacement of the restoration. Factors that contribute to failure could involve the dentist, the dental lab and/or the patient. With the increase of zirconia restorations placed worldwide, clinicians have been beginning to face a new challenge when removing this type of restorations. Also, the improvement in the bonding system can exacerbate the challenge. Dentists usually remove crowns by creating a slot in the buccal, occlusal and lingual/palatal surfaces and then dislodge the crown in two halves. This removal process can be very time consuming when working with zirconia restorations due to the high hardness value of zirconia. Thus, there is a need in the literature for an evidence based approach to effective zirconia crown removal. To assess this, an evaluation of bur qualities such as the grit size, shape or diameter was examined to determine the effect on the cutting efficiency against zirconia restorations.

\section{Statement of the Problem}

Does the grit size or shape of diamond dental bur affect the efficiency of cutting dental zirconia restorations?

\section{Significance of the Problem}

Chair time is one of the most valuable factors in running a dental practice. Cutting zirconia restorations is a very time consuming process and is also a very stressful procedure for both the dentist and the patient. The popularity of zirconia restorations during the last five years will bring a new challenge to dentistry if the material begins to fail. In 2011, a survey showed that $35 \%$ of indirect restorations are either monolithic zirconia or zirconia based restoration. ${ }^{9} \mathrm{~A}$ study in 2012 found that the 5-year survival rate of zirconia based FPDs was $92 \% .{ }^{10}$ In 2015, a systematic review by Le et al concluded that the 5-year survival rate of zirconia based FPDs was 
93.5\% and was comparable to metal ceramic FPDs. ${ }^{8}$ For zirconia based single crowns, Larsson reported 5-year survival rate for zirconia based single crowns to be $95.9 \% .{ }^{6}$ However, complication rate for zirconia based restorations was reported to be $27.6 \%$ in 5 years and chipping of the restoration was the most common complication. ${ }^{8}$ Removal of zirconia restorations might be necessary when dealing to complications or failure in clinic. Many studies have been published in the cutting efficiency of diamond burs in removing different restorative materials, however, limited amount of research was done to evaluate the effectiveness of diamond burs in cutting zirconia crowns.

\section{Hypotheses}

1) The coarseness of dental diamond burs will have an effect on cutting efficiency on 3Y-TZP within 5 minutes.

2) The shape of dental diamond burs will have an effect on cutting efficiency on $3 \mathrm{Y}$ TZP within 5 minutes.

3) The prolonged cutting procedure will have an effect on cutting efficiency on $3 \mathrm{Y}-\mathrm{TZP}$

\section{Null Hypotheses}

1) The bur coarseness will not have an effect on cutting efficiency within 5 minutes.

2) The bur shape will not have an effect on cutting efficiency within 5 minutes.

3) The prolonged cutting procedure will not have an effect on cutting efficiency among the burs in the study within 5 minutes.

\section{Definitions of Terms:}

Sintering: To cause to become a coherent mass by heating without melting. ${ }^{11}$ 
coefficient of thermal expansion: The fractional change in length of a given material per degree change in temperature. ${ }^{11}$

Transformation toughening: An increase in the fracture toughness of partially stabilized zirconia as a result of the transformation of the zirconia crystals in the vicinity of the tip of a propagating crack from the tetragonal phase to the monoclinic phase. ${ }^{11}$

Knoop hardness number: Measure of hardness obtained with a diamond pyramid indenter and rhombic base with included angles of 172.5 and 130 degrees. ${ }^{11}$

Fatigue: To break or fracture a material caused by repeated cyclic or applied loads below the yield limit, also termed brittle failure or fracture. ${ }^{11}$

Low temperature degradation: Slow hydrothermal aging process of zirconia in the mouth that involves transformation from tetragonal phase to monoclinic phase resulting in a reduction of flexural strength. ${ }^{11}$

\section{Assumptions}

1. The sintered 3Y-TZP block are homogenous and identical to 3Y-TZP crowns

2. The burs accurately represent the manufacturers specifications including diameter and diamond particle size.

\section{Limitations}

1. Overheating of electric handpiece with continuous running at 90 seconds.

2. Air turbine handpieces have inconsistent torque when applied to a material compared to electric handpieces.

3. The pressure of the bur exerted on the block cannot simulate variation of clinical pressure exerted from clinician to clinician.

4. Clinical and age degradation of zirconia was not simulated.

\section{Delimitations}

1. an air turbine handpiece is used to avoid overheating.

2. a standardized weight on the rheostat was used for all the burs.

3. A standardized weight was exerted on the block to provide a consistent cutting pressure between the bur and the zirconia block.

4. A homogenous sintered 3Y-TZP was used. 


\section{Chapter II: Literature Review}

\section{History of Dental Ceramics}

At the beginning of the $19^{\text {th }}$ century, Land attempted to provide dentistry with a strong and esthetic crown restoration material by fusing porcelain to Platinum. ${ }^{12}$ Thus beginning the concept of Porcelain fused to metal restorations. These early restorations had several limitations such as metal show through do to a lack of opaque porcelains. Therefore, the esthetics of PFM crowns at that time was still poor and resulted in a gray appearance of the porcelain. ${ }^{13}$ Complicating matters was the need to find a suitable metal to support the porcelain without fracture during the sintering process. Ideally, a metal with a high coefficient of thermal expansion (CTE) similar to that of the overlaying porcelain should be selected. Platinum was the best candidate for PFM crowns at that time because of its high CTE, however, platinum is too soft and could not provide a strong restoration until Palladium alloys were introduced in the fabrication of PFM restorations later in 1959. ${ }^{14 ;} 15$ Also, improvements in ceramics and the addition of leucite containing ceramics provided porcelain with a CTE that is very close to the metal alloy component.

Porcelain fused to metal restorations presented a durable and a strong restoration while being able to meet a high esthetic demand. The strength of the metal provides support to reinforce the brittle porcelain and to minimize failure. However, to provide good esthetic results, the clinician must provide enough space for a sufficiently thick porcelain layer. This could present a challenge to the clinician when treating young patients with large pulp chambers. ${ }^{16}$ Another esthetic challenge for PFM restorations is be the margin placement. PFM margins are considered the least attractive in terms of esthetic and light transmission while all ceramic margins are considered the most attractive. ${ }^{5}$

In 1774, Alexis Duchateau attempted to use ceramics for making denture teeth ${ }^{17}$. Later in 1887 , C.H. Land made the first ceramic crowns and inlays with a platinum foil matrix that would 
be removed before cementation ${ }^{18}$. Improvements in the materials and the process of fabricating the ceramics provided a better and more durable ceramic restorations. Technological improvements have also improved the overall esthetics of ceramic restorations as well. The introduction of vacuum firing has led to less porosity in the porcelain which resulted in more translucent restorations. ${ }^{7}$

All-ceramic restorations have superior esthetics when compared to PFM restorations. ${ }^{19}$ They generally require slightly less reduction in tooth structure due to the lack of metal support, however, more reduction might be required in the lingual surface to provide strength. ${ }^{19}$ Due to the generally low strength of ceramic restorations, they are usually recommended to areas with minimal occlusal load such as the anterior teeth. ${ }^{19}$ Strong ceramics have been used to provide a strong core for all ceramic crowns. This is technique implements an esthetic porcelain veneer layer on a strong ceramic to increase both strength and esthetics. ${ }^{17}$

Many attempts have been made to find the right material for dentistry and overcome the limitation of all ceramic restorations. Dentistry needed a material that is biocompatible, that has high strength and good esthetic and that is easy to fabricate to provide high long term clinical success. Ceramics have three main divisions, (1) Predominantly glassy materials, (2) particlefilled glasses, and (3) polycrystalline ceramics. ${ }^{20}$ Dental ceramics are usually a "composite", meaning a composition of two or more of these divisions. ${ }^{20}$ Highly esthetic dental ceramics are predominantly glassy while the higher strength substructure ceramics are generally crystalline. ${ }^{20}$

Predominantly glassy ceramics have optical properties that are similar to enamel and dentin. The glasses in dental ceramics are mainly derived from feldspar that is based on silica and alumina and therefore is called feldspathic porcelain. ${ }^{21}$ Fillers can be added to the glasses to control the optical properties, enhance mechanical properties or both. The fillers can be either crystalline or particles of another higher melting glass. Different amounts of the filler will have different effect on the ceramic. ${ }^{20}$ Leucite was the first filler to be used in dental ceramics by using $17-25 \%$ mass of leucite as a filler. ${ }^{22}$ It helped raise the coefficient of thermal expansion for the porcelain allowing it to be successfully fired onto a metal substructure. ${ }^{15} \mathrm{~A}$ new leucite reinforced porcelains was developed by Wohlwend and marketed in 1991 under the trade name 
IPS Empress ceramic (Ivoclar-Vivadent, Leichtenstein). ${ }^{23}$ Empress glass ceramic material is a feldspathic ceramic that is reinforced with $40-50 \%$ Leucite by mass. The strength of the material was reported to be around $814 \mathrm{MPa}$. Empress crowns were fabricated using lost wax technique and hot pressing, but more recently, CAD-CAM technology has been used to mill restorations. ${ }^{2}$

In addition to Leucite, the use of aluminum oxide particles has been used to increase the strength of feldspathic glass. This type of stronger porcelain is known as "Aluminous porcelain". Aluminous porcelain was introduced to dentistry by McLean and Hughes in 1965 when they presented the principle of providing a ceramic core with a high strength to reinforce a veneering layer. ${ }^{24}$ Aluminous veneers later have provided very esthetic restorations that resemble natural teeth with a slightly higher strength. ${ }^{24}$

MacCulloch introduced glass ceramics into the fabrication of all ceramic crowns in 1968. ${ }^{25}$ The idea was adopted by Grossman and Adair and was marketed as "Dicor". ${ }^{26}$ Tetrasilicic-fluoromic crystals $\left(\mathrm{K}_{2} \mathrm{Mg}_{5} \mathrm{SiO}_{2} \mathrm{OF}_{4}\right)$ were mixed with the glass powders before firing. The process resulted in precipitation and growth of the crystallites within the glass ${ }^{27}$. However, the color was not stable as they needed surface colorants for shade modifications. ${ }^{2}$ High alumina ceramics were used as a core for glass ceramic restorations and provided high strength, up to $800 \mathrm{MPa}$, but their high opacity was hard to mask and it limited their use for esthetic restorations. ${ }^{23}$

Another glass ceramic was introduced to dentistry using a different filler. The introduction of lithium disilicate $\left(\mathrm{LS}_{2}\right)$ by Ivoclar-Vivadent provided a monolithic restoration that is highly esthetic with decent strength for both anterior and posterior regions. ${ }^{28}$ Incorporating lithium orthophosphate into lithium disilicate increased the strength of the material without affecting the translucency, giving it an average flexural strength of $407 \mathrm{MPa} .{ }^{29}$ The system was first marketed as IPS Empress in the early 1990s and was designed for single unit crowns. ${ }^{29}$ Empress 2 was the second generation of lithium disilicate and was designed for single crowns and anterior bridges. ${ }^{19 ; 29}$ IPS e.max was later introduced as another generation of lithium disilicate restorations with improved physical and optical properties achieved by different firing process. ${ }^{30}$ In a systematic review by Pieger $e t$ al, the survival rate for single crowns was reported to be $97.8 \%$ in 5 years and $96.7 \%$ in 10 years while for FDPs the survival rate was $78.1 \%$ in 5 
years and $70.0 \%$ in 10 years. $^{31}$

Polycrystalline ceramics, such as Aluminum oxide or zirconium oxide, have no glassy components. The atoms are highly packed and provide a tougher and stronger material when compared to glassy ceramics. ${ }^{32}$ Processing of polycrystalline ceramics for dental prostheses was difficult and was facilitated by the improvement of CAD-CAM technology. ${ }^{33}$ Firing shrinkage of the ceramic powder needed to be predicted accurately to provide a well-fitting dental prosthesis. Polycrystalline ceramics are opaque but strong, therefore, they have been used as a substructure for glassy ceramics. ${ }^{34 ; 35}$ However, chipping of the veneering layer was a big disadvantage that contributed to most of the complications with restorations made with polycrystalline ceramic cores. ${ }^{36}$ different factors attributed to chipping of the restorations such as poor core design, weak veneering layer, mismatch in CTE and rapid cooling after porcelain firing. ${ }^{17}$

\section{Zirconia, the "Ceramic Steel"}

Pure zirconium $(\mathrm{Zr})$ is a soft metal that is shiny and silver in color and has an atomic number 40 in the periodic table. Zirconium can be found in nature mostly as a mineral zircon $\left(\mathrm{ZrSiO}_{4}\right)$. Zirconia, which is the zirconium oxide $\left(\mathrm{ZrO}_{2}\right)$ is the mostly used derivative of zirconium in ceramic industry. Zirconia has a high fracture strength and is highly resistant to corrosion. It has a high melting point that makes it a good candidate for high temperature applications. Also, it has been used as an opacifier for ceramics because of its white opaque appearance. $^{37}$

The strength of dental zirconia is attributed to the stabilization of its tetragonal phase at room temperature by using dopants during the process. There are three different phases of zirconia that can be achieved with different temperatures. Zirconia exists in a monoclinic phase at room temperature which is a weak, brittle and chalky phase. By raising the temperature of zirconia gradually, the monoclinic phase transforms to a tetragonal phase at $1170{ }^{\circ} \mathrm{C}$ and then to a cubic as the temperature goes higher than $2370{ }^{\circ} \mathrm{C} .{ }^{38}$ By adding dopants, such as magnesium, yttrium or Cerium, the high temperature phases can be stabilized at room temperature resulting in different mechanical and optical properties. The stabilized cubic phase of zirconia has a 
crystal appearance and is used in jewelry fabrication due to its resemblance to diamond while the stabilized tetragonal phase is opaque and has a high flexural strength value. The transformation from monoclinic phase to a tetragonal phase is accompanied by $4-5 \%$ volume shrinkage.

The potential of zirconia was recognized in 1975 by Gravie et al, who called zirconia "the ceramic steel" due to the high strength that could be achieved if we utilize the cubic and tetragonal phases to their best potential. ${ }^{39}$ Gravie had proposed the idea of a partially stabilized zirconia that includes a stabilized tetragonal phase of zirconia in a cubic phase matrix. Achieving that, a high strength phase of zirconia can be stabilized at room temperature. Different oxides have been used to stabilize the tetragonal phase at room temperature. Yttrium oxide is a common stabilizer for dental applications to produce a metastable tetragonal phase of zirconia at room temperature. The transformation from tetragonal to monoclinic is accompanied by $3 \%$ to $5 \%$ volume expansion. ${ }^{40}$ The toughness and strength of zirconia is increased by suppressing the expansion during the phase transformation and therefore it's called transformation toughening. ${ }^{41}$

Different types of zirconia materials have been developed for dental applications such as Zirconia Toughened Alumina (ZTA), Partially Stabilized Zirconia (PSZ) and Tetragonal Zirconia Polycrystal (TZP). ZTA was first marketed as InCeram which had a relatively low flexural strength of $630 \mathrm{MPa}$ due to it's large pore content. TZP is the most common dental zirconia and has a flexural strength of $800-1000 \mathrm{MPa}{ }^{41}$ The most common stabilizer for TZP is 3 mol\% Yttrium oxide $\left(\mathrm{Y}_{2} \mathrm{O}_{3}\right)$ and is usually referred to as $3 \mathrm{Y}-\mathrm{TZP}$.

\section{Clinical application of zirconia}

Zirconia has been used in dentistry due to its high strength and relative translucency. ${ }^{42}$ Christensen, in 2010, reported a three year survival rate of $81 \%$ for zirconia FPDs. ${ }^{43}$ A more recent study in 2015 by Le et al reported a 100\% 5-year survival rate and $93.3 \%$ 5-year success rate for zirconia FPDs. ${ }^{8}$ Another study in the same year by Sola-Ruiz et al reported that the success rate of $88.8 \%$ in 7 years for zirconia based FPDs. ${ }^{44}$ For zirconia single crowns, a study 
by Gherlone et al reported a success rate of $69.8 \%$ and a survival rate was $100 \% .{ }^{45}$ The reason for the low success rate in this study was the high incidence chipping in the restorations that didn't require the removal of the crown. All the studies come to an agreement that chipping of zirconia restorations was the most common complication.

Sola-Ruiz reported that the most common complication of zirconia FPDs was chipping of the layered porcelain. The rate that was reported in the study was $14.8 \%$ in 7 years. ${ }^{44}$ In another report by Denry, the most common complication of zirconia restorations was chipping of veneering layer with a reported incidence of around 25 to $50 \%$, which is very significant. In some incidents chipping was so severe that it necessitated removing and remaking the restoration. ${ }^{36}$ Some clinicians tried bonding composite to zirconia to alleviate the chipping of the restoration, resulting in some studies tried to evaluate repairing chipped zirconia with composite. ${ }^{46}$ Ribeiro compared different bonding systems and different surface treatments, such as sand blasting, to evaluate repairing of zirconia chipping intraorally with composite resin. The study found that even the strongest bond between composite and zirconia resulted in an extremely low strength bond of less than $11 \mathrm{MPa} .{ }^{46}$

Chipping of zirconia crowns resulted in several investigations to prevent or minimize the problem. In a report by Lohbaur et al, it was found that a thermal shock could be the reason a layered zirconia can fail or chip. ${ }^{47}$ Another study that confirmed the previous finding was done by Tholey et al who found that slow cooling during the final veneering of dental restorations with zirconia frameworks reduces the temperature gradients and residual stresses within the porcelain layer. The study concluded that rapid cooling of zirconia after firing the porcelain layer was most likely the cause of chipping of zirconia. ${ }^{48}$

Monolithic zirconia became a solution to the chipping problem due to the elimination of the veneering layer. A downside to this was that early zirconia oxide materials had limited translucency which caused restoration to appear unesthetic. ${ }^{17}$ A research into materials progressed a new generation of zirconia restorations could be fabricated with different degrees of translucency but the strength has to be compromised if higher translucency is obtained. ${ }^{49}$ However, even with higher translucency, the strength of a restoration is reported to be 850 
$\mathrm{MPa} .{ }^{49}$ The strength of monolithic restoration allowed a more conservative tooth reduction by requiring less space for crown fabrication. Manufacturer recommendation for the monolithic ZirCAD system is a minimum of $0.8 \mathrm{~mm}$ of space. ${ }^{49}$ Less space requirement might be a good advantage especially in cases where there is a limited occlusocervical dimension. In 2001, Goodacre recommended that the occlusocervical dimension of tooth preparation should be at minimum $3 \mathrm{~mm}$ for anterior and premolar teeth and $4 \mathrm{~mm}$ for molars. Adequate occlusocervical dimension is necessary for improving resistance and retention of the crown. Therefore, by requiring less space, monolithic zirconia restoration can be a good material of choice for situations where there is a limitation in the occlusocervical dimensions such as short clinical crowns. ${ }^{50}$

Secondary caries is the most common cause of failures of single crown restorations. The incidence of secondary caries was reported to be $7.4 \%$ in a seven year follow up of 27 anterior FPDs. ${ }^{44}$ In 2014, Tartglia and colleagues ${ }^{51}$ found that in 303 zirconia restorations secondary caries incidence was found to be $1 \%$. However, even though caries is less frequent than chipping, it is considered a major complication and would require replacement of the restoration. ${ }^{52}$

Techniques for zirconia restorations removal have been suggested by different authors such as the Bucco-lingual Dimple technique ${ }^{53}$ or Er:YAG laser Energy ${ }^{54 ; 55 ; 56}$. In the Buccolingual dimple technique, it was suggested that the dentist can create a dimple in the gingival third of both buccal and lingual surfaces with a small round bur to act as a receptacle for the beaks of Baade pliers. The crown would be removed by twisting motion. This technique depends on the retentive features of the crown and might not always work as the author mentions possibility of tooth fracture if too much force was applied to a well retentive restoration. The technique is also contraindicated for cases with excessive bone loss, unfavorable crown/root ratio, or mobility. The Er:YAG laser energy method to debond all ceramic crowns seems to be a very efficient method to solve the problem of retrieving crowns with minimum damage to tooth structure. However, it's only limited to restorations cemented with resin cements. One of the advantages of this method is the short time it takes to remove zirconia restoration. An average time for removing zirconia crown with laser energy was reported to be 253 seconds. ${ }^{56}$ Another advantage would be the ability to retrieve the crown without causing damage to the restoration 
which could be used as a temporary restoration if applicable. However, a major disadvantage of this method is the cost of dental laser technology which limits its availability to dental practitioners.

\section{Cutting efficiency of diamond burs}

With the increase of Zirconia restorations, clinicians are facing a new difficulty when dealing with removing zirconia. Even with our best efforts, failure of a restoration could still happen. Due to the high strength of zirconia polycrystalline material, removing a zirconia restoration, when it is indicated, is a time-consuming procedure. It requires careful judgement to avoid overheating the pulp. It also requires an excellent psychomotor skill, a sound judgement of the amount of coolant to be used and of the rotational speed of the diamond bur. ${ }^{3}$

Diamond burs work by abrasion of the diamond layer on a substrate such as a tooth or a restoration. Due to the superior hardness of diamonds, it is very effective when abrading a surface of a lower hardness level. The abrasion is determined by random distribution of the diamond grains on the bur. An electrolytic bath is used to bond selected diamond grains to the bur shank that is usually made of nickel. The efficacy and quality of the abrasion is determined by the co-axiality, concentric rotation, the shape and diameter of the bur and the grit size. ${ }^{5}$

According to the International Standards Organization's article ISO 7711-3:2004, the grit size is determined by two different technique, sieving and sedimentation. ${ }^{57}$ Sieving is used for macro-grit sizes which are usually above $56 \mu \mathrm{m}$ while the other technique is used for micro-grit size which are below $56 \mu \mathrm{m}$. Sieving is considered the oldest method to determine particle size distribution. The particle size obtained from sieving is usually an approximation of the size distribution. Sedimentation, on the other hand, is a process where particles are deposited into a viscous liquid where the particle's weight is balanced by frictional forces to achieve a constant velocity. When there is a range in particle size, such as in diamond burs, sedimentation becomes a complicated process which will make it challenging to isolate one specific grain size. ${ }^{38}$ For this reason, the diamond particles are found in a range of size in the diamond bur. The ranges of the diamond grit size for ultrafine, extra-fine and fine diamond burs are 4-14, 10-36, and 27-76 $\mu \mathrm{m}$ 
respectively. While the grit size ranges for medium, coarse and super coarse diamond burs are 64-126, 107-181 and 151-213 $\mu \mathrm{m}$ respectively. Overlapping is unavoidable because of the difficulty of the separating the grain sizes. The median of the range is usually what is reported by manufacturers as the grit size of the diamond bur. ${ }^{57}$

Assessing cutting efficiency of dental burs is a subject that has several challenges. There are many uncontrollable operating parameters such as the individual dental technique, differences in dental hard tissues, rotation speed, applied pressure, turbine air pressure and differences in handpieces. ${ }^{58}$ Some of the studies involved modified milling tests such as a fixed speed, 60,000 to 300,000 rpms, a fixed load, 50-150 grams, or a fixed angle that was 90 degrees $^{59 ; 60 ; 61}$. Different factors were noticed to influence the cutting efficiency of a dental diamond bur. These factors are 1) bur profile, 2) grit size, 3) bur manufacturer, and 4) method of manufacturing. ${ }^{62}$ In a study by Siegel and Von Fraunhofer, three different grit sizes were tested against machinable glass ceramics (Macor, Corning Inc.). The authors used super coarse, coarse and medium grit size burs to cut the ceramic using a digital handpiece. The burs were used to make three cuts of $13 \mathrm{~mm}$ each and the authors recorded the rate of each cut. All the diamond grit sizes showed a decrease in the cutting rate with prolonged cutting. $50 \%$ reduction in cutting rate was noticed with the medium bur after the first cut, while coarse and super coarse grit sizes showed $35.3 \%$ and $25 \%$ reduction respectively. Authors concluded that cutting efficiency depends on the grit size and the duration of the cutting. They also found that over short cutting periods, medium, coarse and super coarse diamond burs all had comparable cutting rates. ${ }^{63}$ This finding might affect clinician's decision whether it is time efficient to use the same bur for a long period of time.

Heat generation is always a concern when using diamond burs. A dentist must be cautious and avoid overheating the tooth when cutting a tooth or a restoration. Different variables can affect heat generation of the diamond burs such as the bur diameter and the grit size. Large diameter diamond burs can produce less heat as they develop greater peripheral velocity and dissipate more heat. ${ }^{5}$ In a study by Ottl and Lauer, the temperature response in the pulp chamber was measured during use of high speed handpiece and diamond burs. There was an association with increased heat and increased grit size. The authors found that fine grit burs 
caused an average increase of $0.8^{\circ} \mathrm{C}$. Medium, coarse and super coarse grit sizes caused an increase of $1.3,1.5$ and $1.8{ }^{\circ} \mathrm{C}$ respectively. The study presented two different facts. First, was that heat produced during cutting tooth structure can reach the pulp chamber and therefore could cause damage to the pulp if not controlled. The other fact is that dissipation of heat through tooth structure to the pulp chamber is different between grit sizes. The greater grit sizes such as coarse or super coarse burs produce more heat when compared to medium and fine grit sizes. ${ }^{64}$ However, the greater cutting efficiency of super coarse and coarse diamond bur would translate in a shorter working period which means the tooth is not subject to prolonged thermal attack. A prolonged thermal attack might cause irreversible damage to the pulp. It was recommended that coarse and super coarse diamond burs should be used for cutting while fine burs for finishing the tooth preparation. ${ }^{5}$

Choice of the rotary instrument also plays a role in cutting efficiency of diamond burs in dentistry. The introduction of the dental handpiece to dentistry in 1868 by Green was a significant advancement. Later improvement of the dental handpiece became available with higher speeds. ${ }^{65}$ At the beginning, dental handpieces were only air driven rotary instruments until the 1960s when electric motor handpieces were developed. However, electric motor handpieces were not popular in the united states until recently. More studies started comparing the cutting efficiency between air driven handpieces and electric driven handpieces. In a study done by Choi et $a l^{66}$, a comparison was made between the two handpieces in cutting different substrates. The authors used multiple substrates to simulate different materials in the mouth such as machinable glass, amalgam, different alloys, alumina oxide, and zirconia. The electric handpiece was found more efficient in cutting high noble alloys, amalgams and machinable glass. However, there was no difference in cutting efficiency between the electric handpiece and the air driven handpiece in cutting zirconia or alumina.

Pressure of the handpiece during operation has a great effect on cutting efficiency. It was reported that dentists generally exert a force between 50 to $150 \mathrm{~g}$ when using diamond burs. ${ }^{59}$ Siegel and Von Fraunhofer assessed the applied forces of three prosthodontists and three general dentists. They have found that the mean of the applied force to be $99.3 \mathrm{~g}$ which is within the reported ranges. ${ }^{67}$ In another study by the same authors, they evaluated the cutting efficiency of 
diamond dental burs by using different loads on the handpiece. The authors applied loads of 44, 91.5 and $183 \mathrm{~g}$ at the bur/ceramic interface. The authors found a significant increase in cutting efficiency when the load was increased from $44 \mathrm{~g}$ to 91.5 grams while there was no further effect when the load was increased from $91.5 \mathrm{~g}$ to $183 \mathrm{~g}$. Therefore, the authors suggest that the optimum handpiece pressure with diamond burs is $100 \mathrm{~g} .{ }^{68}$

Cutting efficiency of the diamond bur can also be affected by repeated use of the bur. Diamond burs are marketed for either single-use of multiuse depending on the manufacturer. Single-use refers to use on a single patient where multiuse refers to ability to sterilize the bur to be used later on another patient. Siegel and Von Fraunhofer ${ }^{67}$ have compared cutting efficiency between the single use and multiuse diamond by making ten 30 -seeonds cuts on Macor. When comparing medium grit diamond burs, the efficiency was comparable between single-use and multiuse. Rotella et $a l^{69}$ have also compared between single-use burs and multiuse burs by using electrical and air turbine handpieces. The authors evaluated the effects of cleaning and sterilization of the burs to their cutting efficiency on machinable glass ceramics that simulates tooth structure. It was found that the cutting rate was decreased with repeated use of the bur. Cleaning and sterilization improved the average performance. This finding is explained by possible removal of debris that clogged into the diamond bur.

Previous studies relied upon simulating tooth structure as the substrate for testing the cutting efficiency of diamond burs. In a study done by Nakamura et $a l^{70}$, cutting efficiency of diamond burs was tested with different restoration materials. The authors used zirconia, lithium disilicate glass ceramic and Leucite glass ceramic for the study. They found that zirconia took a significantly longer time to be cut than the other materials with the same thickness. Different cutting forces were also tested such as $0.9 \mathrm{~N}$ and $1.8 \mathrm{~N}$ and it was found that the $1.8 \mathrm{~N}$ of cutting force resulted in larger depth cuts only in the first 30 seconds but resulted in smaller depth cuts after 5 minutes when compared to $0.9 \mathrm{~N}$. This finding led to a conclusion that an increase in the force will cause damage to the diamond particles on the diamond burs. Also, it was found that super coarse diamond burs were more efficient than coarse burs when $0.9 \mathrm{~N}$ cutting force was used while $1.8 \mathrm{~N}$ cutting force showed that coarse diamond burs were more efficient. The 
authors explained this finding by proposing that coarse diamond burs were more resistant to damage. ${ }^{70}$

In another study on cutting zirconia, Yin et al ${ }^{71}$ evaluated different grit sizes and their cutting efficiency on Yttrium stabilized tetragon zirconia polycrystals. The authors used ultrafine $(10 \mu \mathrm{m})$, fine $(41 \mu \mathrm{m})$ and coarse $(172 \mu \mathrm{m})$ diamond burs and performed a series of 10 seconds cuts for a total of 300 seconds and plotted the depth of the cut every 10 seconds. The authors ultrasonically cleaned the burs every 30 seconds to remove any clogged debris. It was found that the coarse burs had a removal rate that was approximately 50\% higher than fine burs and 150\% higher than ultrafine burs. Also, the ultrasonic cleaning of the burs did not have any effect on the removal rate. The authors also noted that the removal rate with coarse burs stayed constant in the first 30 seconds but started decreasing after that. In 300 seconds, the removal rate was reduced by 70,90 and $80 \%$ for the ultrafine, fine and coarse burs respectively.

Yin $e t a l^{72}$ evaluated the reduction on cutting efficiency of the diamond burs on zirconia restorations. They found $80 \%$ reduction in cutting efficiency with coarse diamond burs. When examined with scanning electron microscope, the diamond burs showed four types of wear damage: grit dislodgment, grit fracture, attritous wear and matrix abrasion. Grit dislodgment is affected by the bonding strength between the diamond particles and the shank matrix. Yin found through the SEM examination that grit dislodgment contributed to $9 \%$ of the damage to the coarse diamond burs used to cut zirconia. Grit fracture was found to be the most dominant wear process with fine and coarse burs. Yin concluded that as the diamond grit size was increased, the occurrence of brittle fracture increased. This might explain our finding in this study where a coarse bur, bur E, was the most efficient bur through 5 minutes.

The high hardness of zirconia is the main reason for its difficult removal. There is a direct association between hardness and wear resistance as the higher the hardness value is, the more wear resistant the material is. The two main mechanisms for removal of ceramic material are grain pullout and/or cracking. Grain pullout is usually found in polycrystalline ceramics with weak boundaries. Cracking is a fracture caused by abrasion, erosion, or gouging. ${ }^{73}$ Machining 
hard ceramics can be an expensive procedure because usually diamond tools of superior hardness are necessary. ${ }^{38}$

In a study by Alexander ${ }^{74}$ in West Virginia University, cutting efficiency of parallel shaped diamond burs was tested on 3Y-TZP specimens. The author used a different method of measuring the rate of the diamond burs cutting efficiency by utilizing a Linear Variable Differential Transformer (LVDT) to measure the linear displacement of the zirconia specimen continuously during the experiment. The value of this method was that it measured the cutting rate immediately without having to stop the experiments every 10 seconds to make measurements. This was believed to minimize errors produced in the experiment and produce a continuous monitoring of distance versus time which permitted measuring the rate of depth cuts at any giving time by calculating the slope of the produced distance vs time graph. In the experiment, $1.4 \mathrm{~mm}$ diameter was used with 7 different types of burs of different particle sizes. It was found that super coarse diamond burs were the most efficient in cutting 3Y-TZP through 5 minutes.

As stated previously, the efficacy and quality of the diamond bur is determined by the shape and diameter of the bur as well as the grit size. ${ }^{5}$ Alexander's study, ${ }^{74}$ looked only at parallel shaped diamond burs with a diameter of $1.4 \mathrm{~mm}$, to limit the risk of confounding data due to bur taper when comparing girt size. As a result, the use of differently shaped diamond burs could yield different results. While many of the studies have tested different grit sizes and cutting forces of the diamond burs, none had examined the effect of the shape of the diamond bur on the cutting efficiency of dental zirconia. 


\section{Chapter III: Materials and Methods}

\section{Research Design}

From two different manufacturers, (Brasseler, Savannah, GA) and (Komet, Rock Hill, SC), seven tapered diamond burs were selected based the diamond particle size and the dimension of the bur shank. The reported diameter size that was selected was $1.4 \mathrm{~mm}$. Selected diamond grits and manufacturer of the burs are listed in Table 1. Ten replicates of each bur were used during the study. 7 rectangular IPS e.max ZirCAD blocks with a dimension of $11.34 \times 12.5 \times 31.7 \mathrm{~mm}$ were sintered according to manufactures instructions (Ivoclar Vivadent, Buffalo, NY).

\begin{tabular}{|c|c|c|c|c|}
\hline Letter assignment & Manufacturer & Coarseness & $\begin{array}{c}\text { Grit size } \\
\qquad \mu \mathrm{m}\end{array}$ & Name \\
\hline A & Brasseler & Super coarse & 150 & 5856.31 .014 \\
\hline B & Brasseler & Coarse & 125 & 6856.31 .014 \\
\hline $\mathrm{C}$ & Brasseler & Medium & 100 & 856.31 .014 \\
\hline $\mathrm{D}$ & Komet & super coarse & 181 & 5856.FG.014 \\
\hline $\mathrm{E}$ & Komet & Coarse & 151 & 6856.FG.014 \\
\hline $\mathrm{F}$ & Komet & Medium & 107 & 856.FG.014 \\
\hline G & Brasseler & Duracut* & 151 & 6856.DC.014 \\
\hline
\end{tabular}

Table 1. Tapered diamond burs used in the experiment. 


\section{Construction of Apparatus}

An apparatus that was constructed by Alexander in a previous study was used to perform the experiment. ${ }^{74}$ The apparatus consists of two major parts, a wooden base where a handpiece can mounted on and a wooden platform with four aluminum wheels where the zirconia specimen can be placed (Fig 1). Weights can be attached to the wooden platform to pull the zirconia toward the handpiece. A high-speed air turbine handpiece is mounted on the wooden base. To measure the linear displacement, the apparatus utilizes a Linear Variable Differential Transformer (LVDT) core. An extension of the platform goes through the core to allow reading of the displacement.

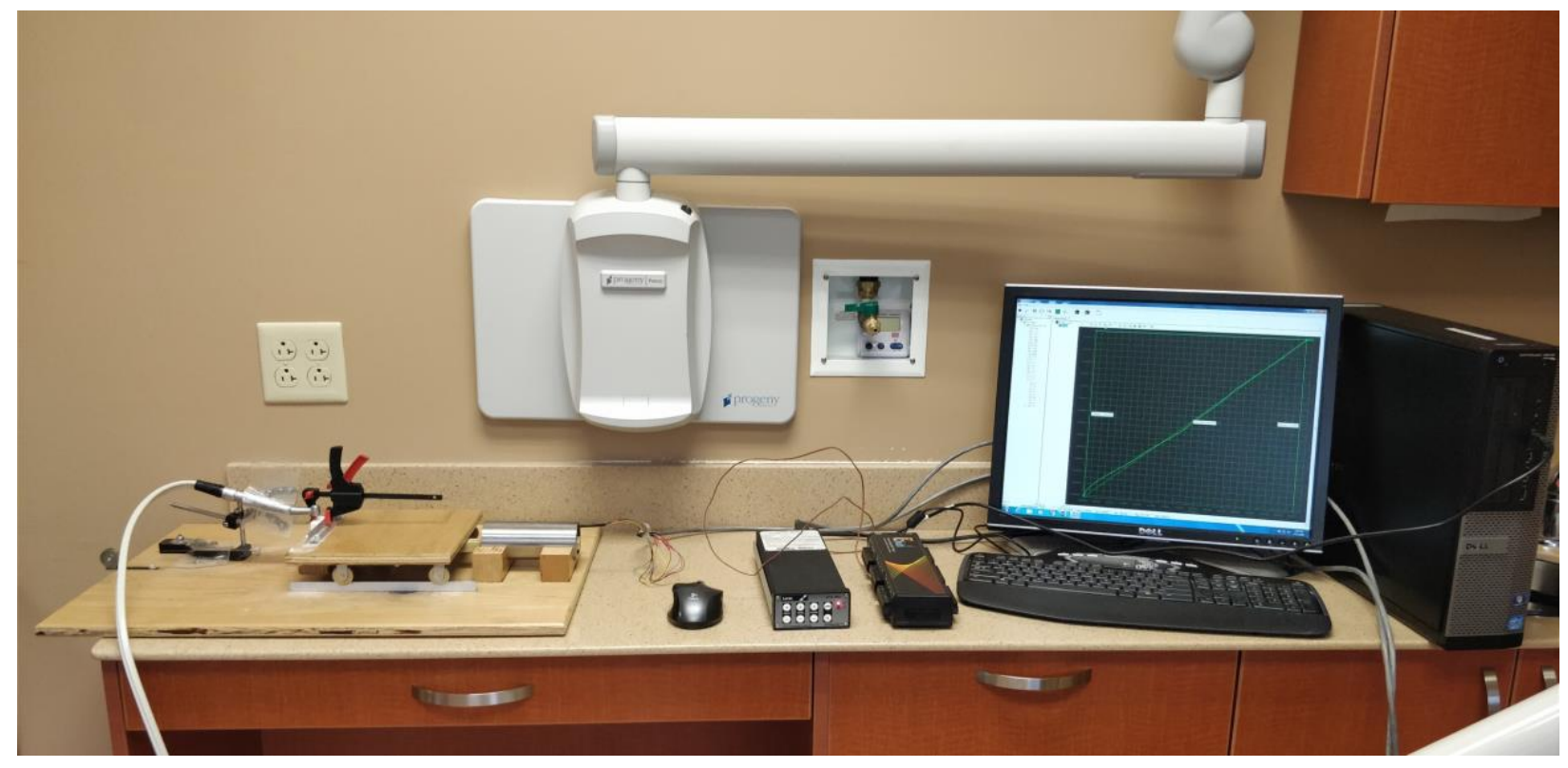

Figure 6 The setup of the experiment. From left to right, apparatus, LVDT signal, personal Daq/3000 and the computer running Daq/3000 software.

A Lucas Schevitz 503XS-A LVDT with an ATA-2001 Signal Conditioner (Measurement Specialties, Hampton, VA) was used to measure the linear displacement of the moving platform. The reading output was in Voltage. A Personal Daq/3000 series data acquisition device (Measurement Computing, Norton, MA) reads the output in volts through different channels. To 
convert the output into distance, a relationship between the voltage and the distance needed to be obtained by moving the platform through an already measured distance and recording the voltage change. The Daq software allows reading through different channels of the LVDT with wider to narrower ranges of readings and with different Voltage/millimeter relationships. After 15 trials, channel "9" was shown to be the most accurate and most consistent channel with an output of voltage that can be converted to distance as $1 \mathrm{~mm}=0.625 \mathrm{~V}$. In the software, channel 9 was selected to read the voltage output. During the experiment, the personal Daq device would read the rea time output generated by the LVDT conditioner and would plot the measured voltage over time.

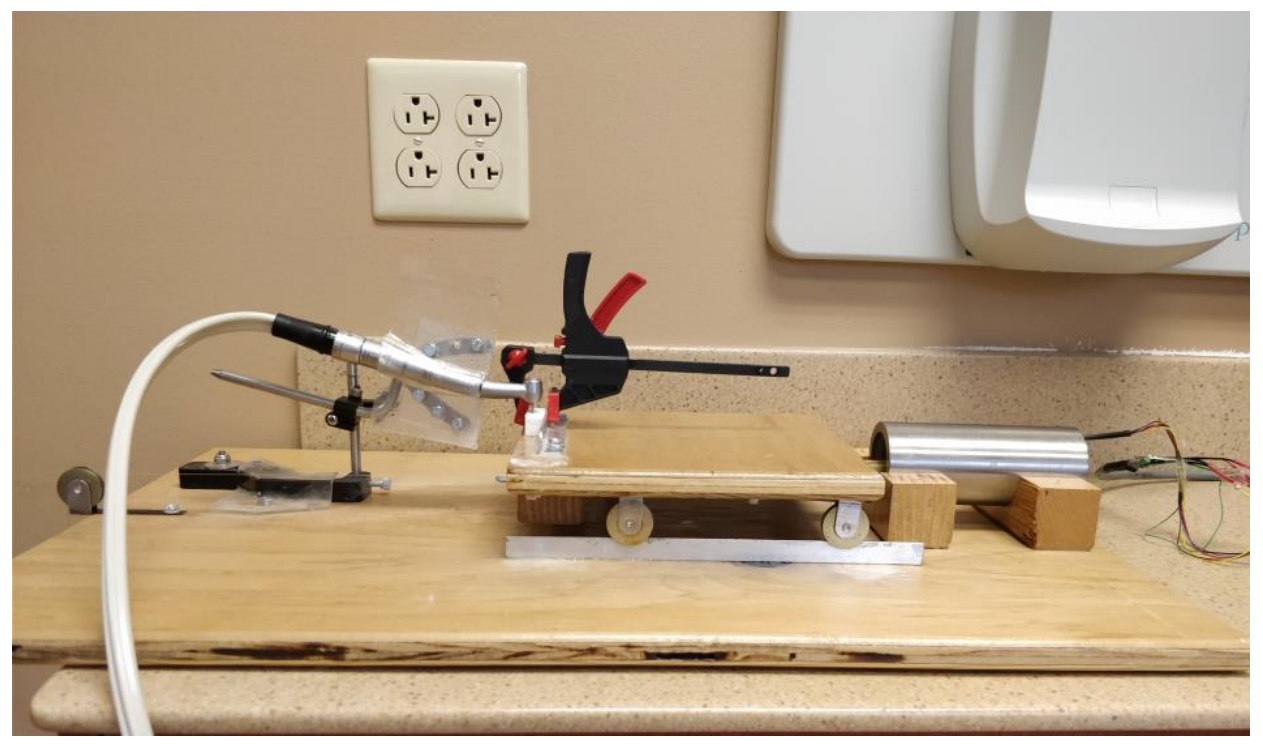

Figure 7. Experiment apparatus.

\section{Protocol}

Burs and zirconia specimens were selected randomly. The zirconia specimens were mounted into the platform with a clamp (Fig 2). The tested bur was paralleled to the specimen and adjusted to a $1.5 \mathrm{~mm}$ depth cut. A $0.9 \mathrm{~N}$ force was then exerted on the $3 \mathrm{Y}$-TZP in the direction of the bur by vertically suspending 91 grams of fishing weights over a pulley at the end of the wooden base. An additional 1.25 grams of weight was added to overcome breakaway 
friction of the platform. The output recording through the Daq was initiated for 2 seconds before exerting pressure on the rheostat. The two second delay allowed a recording of a zero position of the LVDT. Maximal pressure was used on the rheostat using a heavy brick for all the tests. A measured coolant spray rate of $16 \mathrm{~mL} / \mathrm{min}$ for a continuous 300 seconds. At the end of each interval, the data file was saved in an excel spread sheet and the next bur in the series would be placed and the zirconia block was adjusted to expose an uncut surface and the process was repeated (Fig 3).

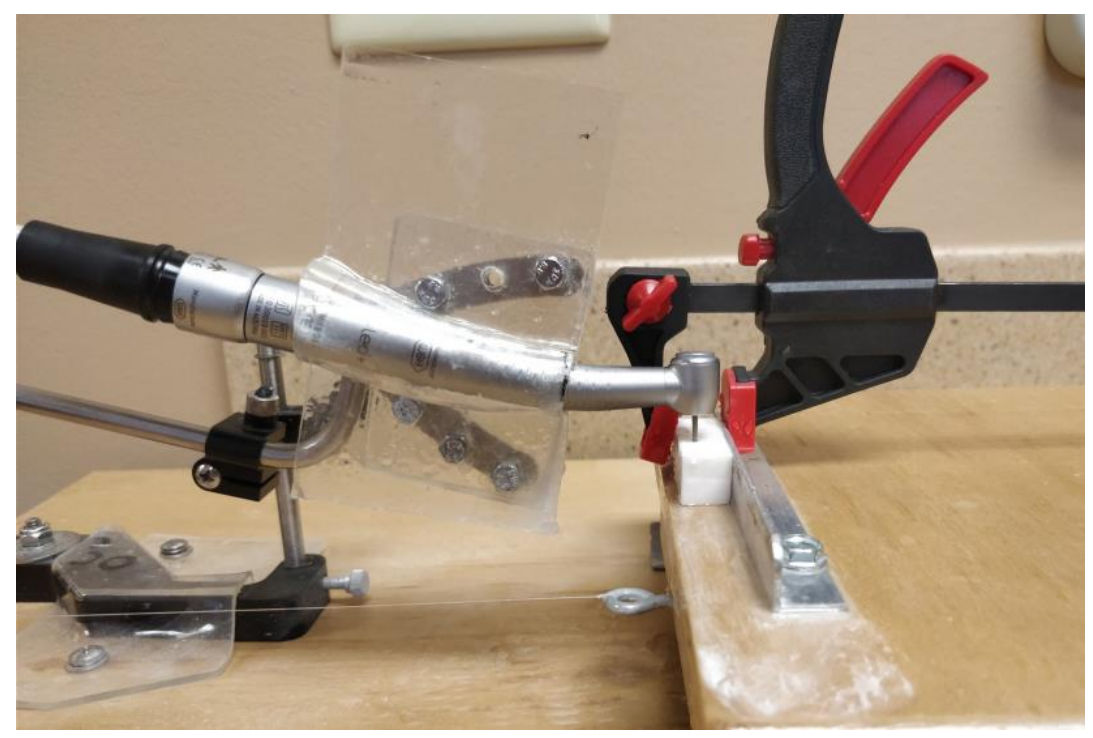

Figure 8. The zirconia specimen mounted on the platform

The ten replicates of seven burs were used to obtain data of recorded voltages measured from time zero to 5 minutes with a measurement taken every sixth of a second. The recorded voltages were converted into distance using the earlier obtained relationship of $1 \mathrm{~mm}=0.625 \mathrm{~V}$. The slope of the best fit lines for each replicate was calculated for 3 time intervals. The slope of the line, which would be the rate in millimeters per second, was used for comparison between and within the test variables and can be interpreted as the steeper the slope then the greater the cutting efficiency. The four periods used were: Period 0 ( $0-2$ seconds), Period 1 (2-100 seconds), Period 2 (100-200 seconds), and Period 3 (200-300 seconds). Period 0 reflects the two second lapse before cutting to verify a true start position with the LVDT, therefore, it was not included 
in the statistical analysis. A direct comparison between 5 burs used in the current study was made against their corresponding parallel burs from Alexander's study ${ }^{74}$ since the same protocol was followed (Table 3). Cutting data was obtained from the previous study to evaluate if there was a significant difference between tapered and parallel burs in cutting efficiency on 3Y-TZP.

\begin{tabular}{|c|c|c|c|c|c|}
\hline $\begin{array}{c}\text { Tapered } \\
\text { bur }\end{array}$ & $\begin{array}{l}\text { Corresponding } \\
\text { parallel bur from } \\
\text { Alexander's }^{74}\end{array}$ & Manufacturer & Coarseness & $\begin{array}{l}\text { Grit size } \\
\qquad \mu \mathrm{m}\end{array}$ & label \\
\hline A & A & Brasseler & Super coarse & 150 & $\mathrm{SCb}$ \\
\hline B & $\mathrm{C}$ & Brasseler & Coarse & 125 & $\mathrm{Cb}$ \\
\hline D & G & Komet & super coarse & 181 & SCk \\
\hline $\mathrm{E}$ & $\mathrm{E}$ & Komet & Coarse & 151 & Ck \\
\hline F & $\mathrm{F}$ & Komet & Medium & 107 & $\mathrm{Mk}$ \\
\hline
\end{tabular}

Table 2. Selected tapered burs and the corresponding parallel burs from a previous study. ${ }^{74}$

\section{Statistical Analysis}

A mixed-effect ANOVA to define the variables' effect on cutting efficiency was used to compare the slope lines. The variables showing significance were further evaluated using a posthoc Tukey-Kramer Honestly Significant Difference (Tukey-Kramer HSD) to assess differences between pairs of means. Also, the average distance traveled by the burs through the 5 minutes was obtained from Alexander's study ${ }^{74}$ to be compared to 5 burs used in this study which has the same characteristics except that they differ in shape. One-way ANOVA was completed on the similar burs to evaluate if there is a significant difference. The statistic software used to evaluate the data was JMP ${ }^{\circledR}$ Pro Version 13.1 (Cary, NC). 


\section{Chapter IV: Results and Discussion}

\section{Results}

The traveled distance of each bur in 5 minutes was averaged among the samples. The distance of each bur as a function of time can be seen in (Fig 4) which represents the overall trend of cutting efficiency. Average distance traveled by the bur through the 5 minutes was calculated (Fig 5). The longest distance that was traveled was obtained with bur type E (6856/Coarse/151 $\mu \mathrm{m})$ which resulted in an average depth cut of $4.35 \mathrm{~mm}$ while Type $\mathrm{C}(856 /$ medium $/ 100 \mu \mathrm{m})$ resulted in the shortest average depth cut that was $2.04 \mathrm{~mm}$. burs D and $\mathrm{G}$ had the very close average depth cut of 3.96 and $3.90 \mathrm{~mm}$ respectively. Bur A (5856/Super coarse/ $150 \mu \mathrm{m})$ and bur B $(6856 /$ coarse $/ 125 \mu \mathrm{m})$ resulted in almost similar average depth cuts of $2.58 \mathrm{~mm}$ and $2.52 \mathrm{~mm}$ respectively. 


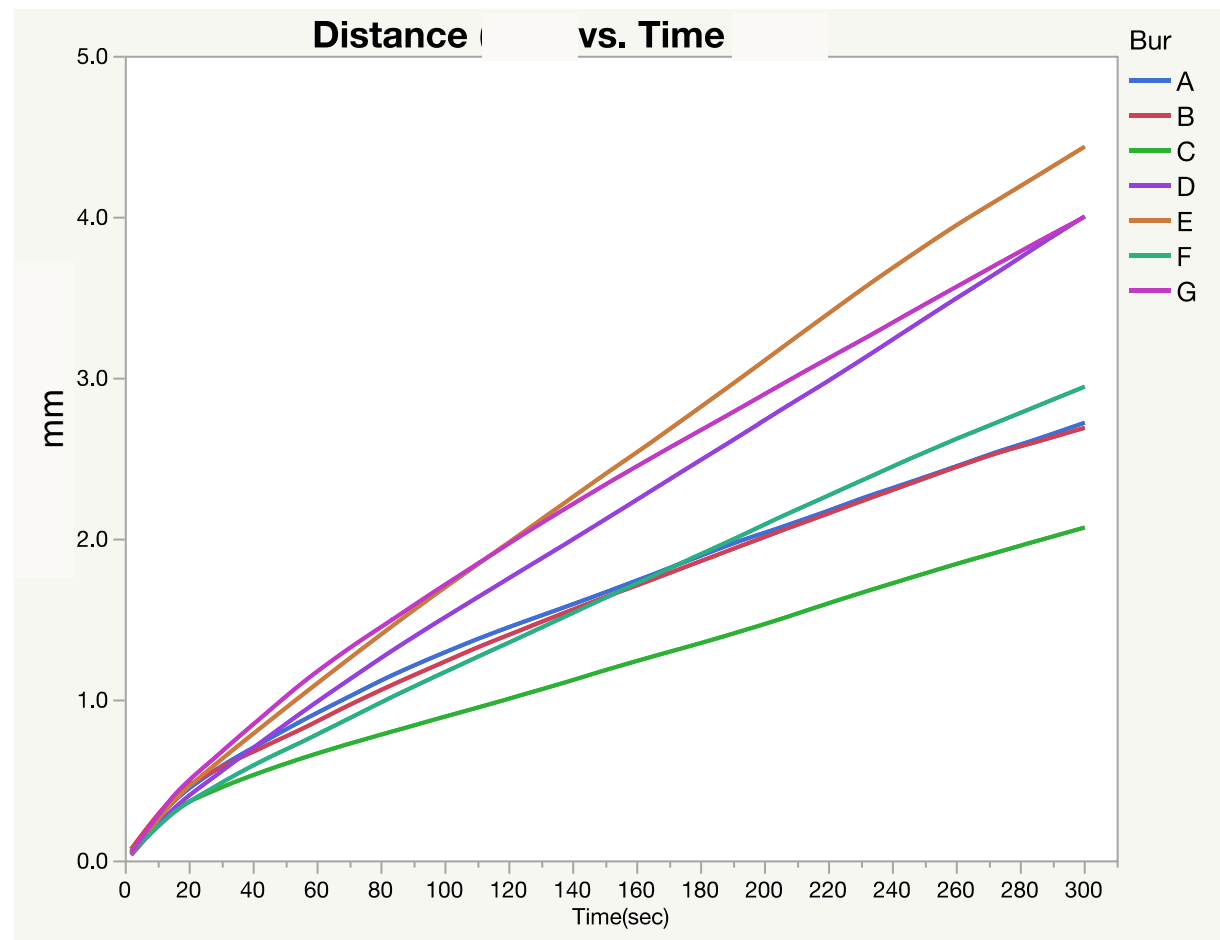

Figure 9. Averaged cutting efficiency of test burs over 5 minutes. (JMP/Pro Ver13.1, SAS Inst. Inc., Cary, NC). 


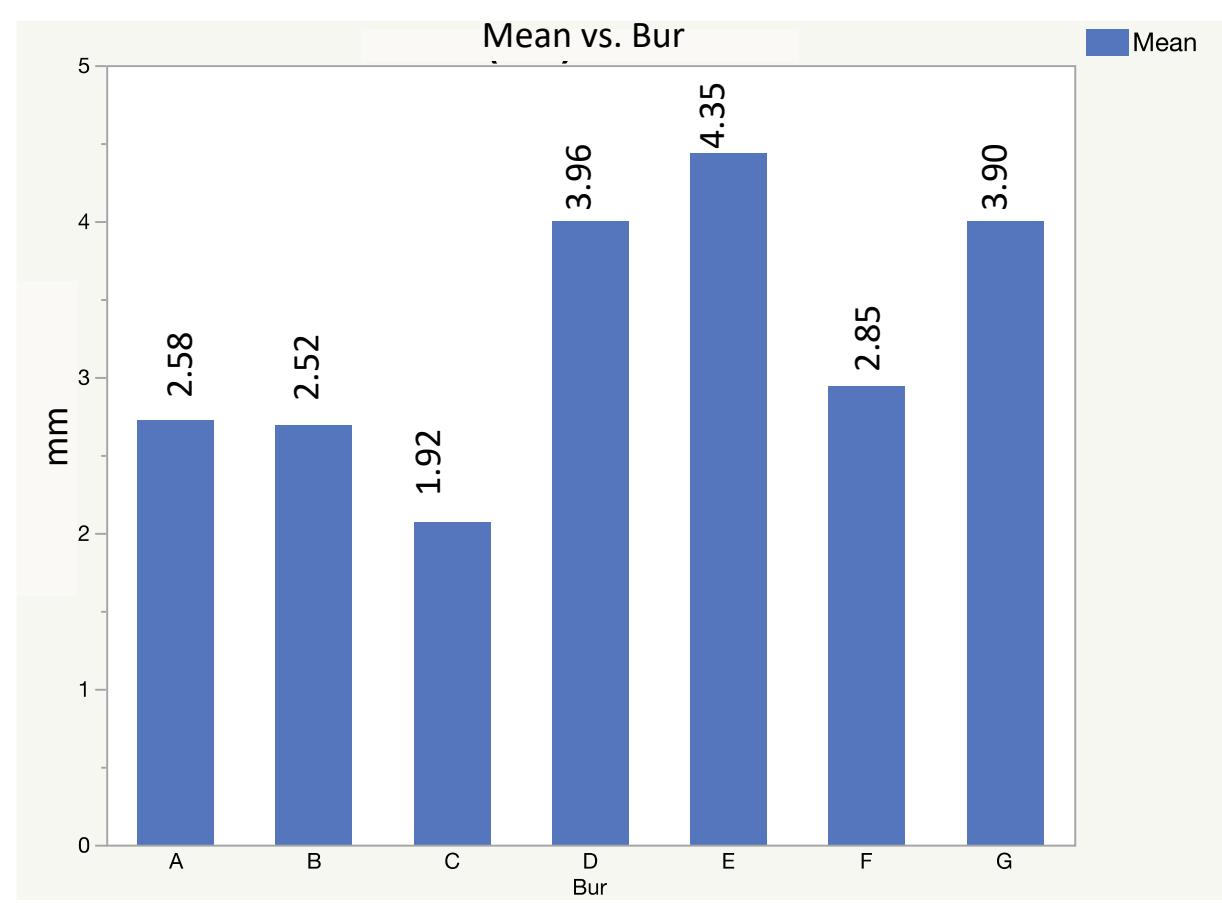

Figure 10. Averaged distance cut of each bur group after 5 minutes. (JMP/Pro Ver13.1, SAS Inst. Inc., Cary, NC).

A Mixed effect ANOVA test was completed (Table 3). Statistically significant effects on cutting efficiency were noticed among the seven diamond burs and among the periods. No significant difference was noticed when evaluating the interaction between the effects of burs and periods on cutting efficiency, meaning that all the burs showed the same trend of decline between time periods. A Tukey-Kramer HSD (Table 4) was completed to show the significance between the seven bur groups. In a descending order, bur types E (6856/Coarse/ $151 \mu \mathrm{m}), \mathrm{D}$ (5856/super coarse/ $181 \mu \mathrm{m})$ and G (6856DC/Dura cut/ $151 \mu \mathrm{m})$ were significantly more efficient in cutting the $3 \mathrm{Y}$-TZP in 5 minutes compared to burs types $\mathrm{F}(856 /$ medium/107 $\mu \mathrm{m}), \mathrm{A}$ (5856/Super coarse/ $150 \mu \mathrm{m})$, B (6856/coarse/125 $\mu \mathrm{m})$ and C (856/medium/100 $\mu \mathrm{m})$. Also, bur types $\mathrm{F}$ was more significantly efficient than bur type $\mathrm{C}$. 


$\begin{array}{lrrrrr}\text { Variables } & \text { Nparm } & \text { DF } & \begin{array}{r}\text { Sum of } \\ \text { Squares }\end{array} & \text { F Ratio } & \text { Prob > F } \\ \text { Bur } & 6 & 6 & 0.00165630 & 27.7423 & <.0001^{*} \\ \text { Period } & 2 & 2 & 0.00040976 & 20.5900 & <.0001^{*} \\ \text { Period*Bur } & 12 & 12 & 0.00007685 & 0.6436 & 0.8030\end{array}$

* Represents significant differences at the $\mathrm{P} \leq 0.05$ interval.

Table 3. Mixed Effects ANOVA between burs, periods and period vs. bur. (JMP/Pro Ver13.1, SAS Inst. Inc., Cary, NC).

\begin{tabular}{|c|c|c|c|c|}
\hline Bur & & & $\begin{array}{l}\text { Distance } \\
(\mathbf{m m})\end{array}$ & $\begin{array}{c}\text { Rate } \\
(\mathrm{mm} / \mathrm{sec})\end{array}$ \\
\hline $\mathbf{E}$ & A & & $4.35 \mathrm{~mm}$ & 0.0145 \\
\hline D & A & & $3.96 \mathrm{~mm}$ & 0.0132 \\
\hline G & A & & $3.90 \mathrm{~mm}$ & 0.0130 \\
\hline $\mathbf{F}$ & B & & $2.85 \mathrm{~mm}$ & 0.0095 \\
\hline $\mathbf{A}$ & B & C & $2.58 \mathrm{~mm}$ & 0.0086 \\
\hline B & $\mathrm{B}$ & $\mathrm{C}$ & $2.52 \mathrm{~mm}$ & 0.0084 \\
\hline $\mathrm{C}$ & 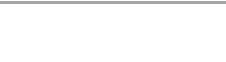 & $\mathrm{C}$ & $2.04 \mathrm{~mm}$ & 0.0068 \\
\hline
\end{tabular}

*Burs not connected by the same letter showed significant differences

Table 4. Tukey-Kramer HSD defining significance between burs through the 5 minutes. (JMP/Pro Ver13.1, SAS Inst. Inc., Cary, NC).

When evaluating the difference between time periods, a Tukey-Kramer HSD (Table 5) shows a significant difference between the periods. The bur types were significantly more efficient during Period 1 when compared to Period 2 and Period 3 while there was no significant difference between Period 2 and Period 3. When comparing burs and time periods simultaneously, no significant difference was found which means all the burs followed the same trend between the periods (Fig 6). 


$\begin{array}{cccc}\text { Period * } & & \begin{array}{c}\text { Rate } \\ (\mathbf{m m} / \mathbf{s e c})\end{array} \\ 1 & \text { A } & & 0.0125 \\ 2 & & \text { B } & 0.0097 \\ 3 & & \text { B } & 0.0093 \\ \text { * Periods not connected by the same letter showed significant differences }\end{array}$

Table 5.Tukey-Kramer HSD defining significance between periods.(JMP/Pro Ver13.1, SAS Inst. Inc., Cary, NC).

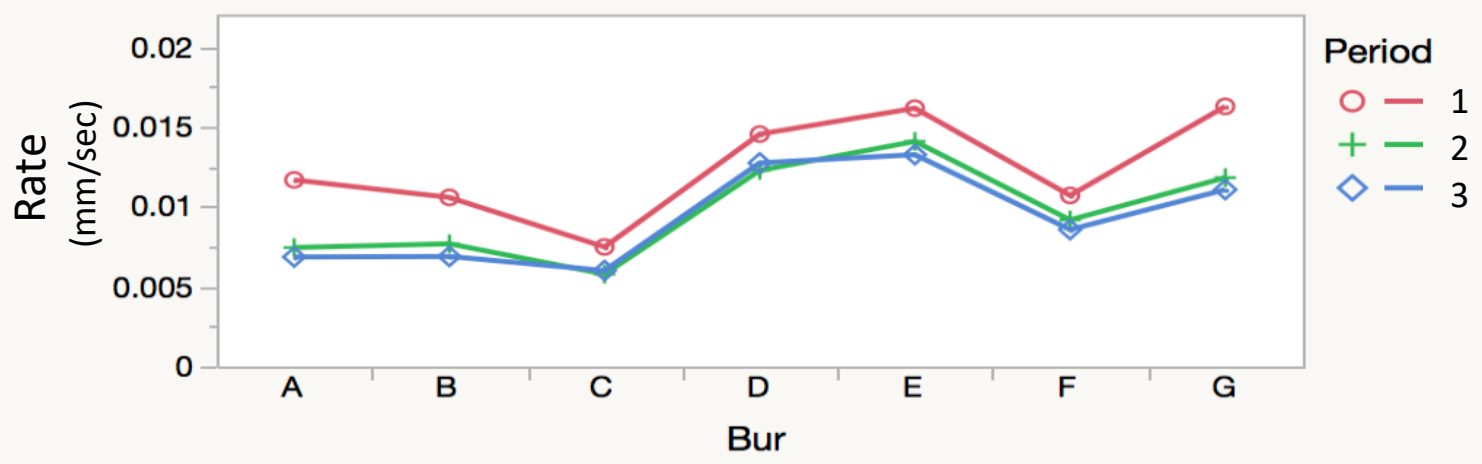

Figure 6. Average cutting efficiency for bur groups in each Period. (JMP/Pro Ver13.1, SAS Inst. Inc., Cary, NC).

When looking at Figure 4, it can be noticed that the burs behaved differently in Period 1 when compared to the whole time. Another statistical analysis was done for Period 1 to see if there was a significant difference in behavior. A Tukey-Kramer HSD test was completed to show the significance between the seven bur groups during Period 1(Table 6). A different pattern was noticed as bur type $\mathrm{G}$ had the highest rate in Period 1. However, burs G, E and D were not significantly different. Burs $\mathrm{G}$ and $\mathrm{E}$ were significantly different than all the other types except bur D. 


\begin{tabular}{|c|c|c|c|c|c|}
\hline Bur* & & & & & $\begin{array}{c}\text { Rate } \\
(\mathrm{mm} / \mathrm{sec})\end{array}$ \\
\hline G & A & & & & 0.0163 \\
\hline $\mathbf{E}$ & A & & & & 0.0161 \\
\hline D & A & B & & & 0.0145 \\
\hline $\mathbf{A}$ & & B & $\mathrm{C}$ & & 0.0117 \\
\hline $\mathbf{F}$ & & & $\mathrm{C}$ & D & 0.0107 \\
\hline B & & & $\mathrm{C}$ & D & 0.0106 \\
\hline C & & & & D & 0.0075 \\
\hline
\end{tabular}

* Burs not connected by the same letter showed significant differences

Table 6. A Tukey-Kramer HSD defining differences between burs in Period 1. (JMP/Pro Ver13.1, SAS Inst. Inc., Cary, NC).

To further evaluate whether the shape of the burs could have a difference in the efficiency of the bur, data was obtained from Alexander's study ${ }^{74}$ to compare if there was a significant difference. In Alexander's study, the burs were parallel sided but in the present study, tapered burs were utilized. Only 5 of the parallel sided burs were available in tapered shape from the selected manufacturers. The average distance traveled by the burs through the 5 minutes can be seen in Figure 7. Even that there was some difference between the burs, a one-way ANOVA showed that the difference was not significant between the parallel sided burs and the tapered burs (Table.7). 


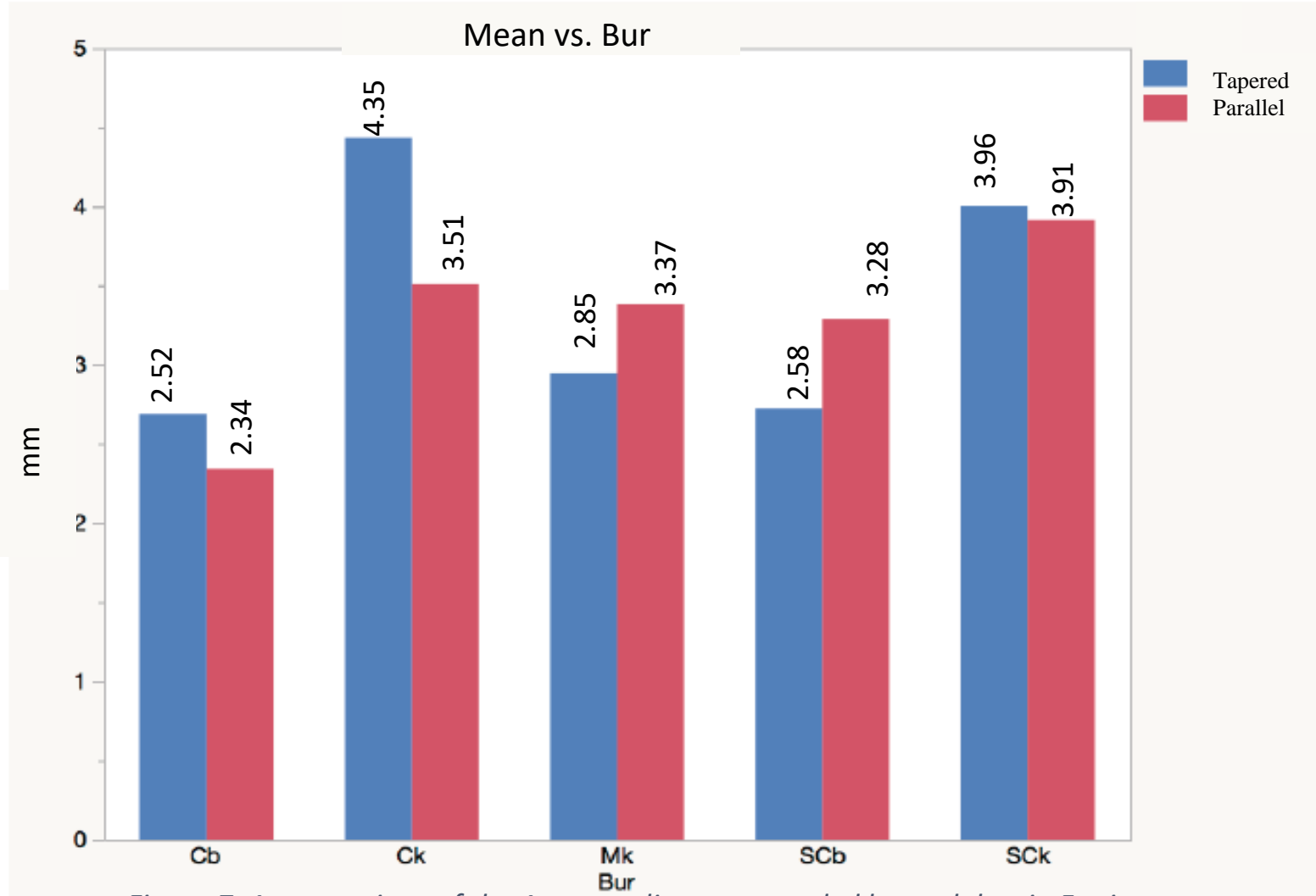

Figure 7. A comparison of the Average distance traveled by each bur in 5 minutes between taper burs and parallel burs from Alexander's study. Cb; coarse Brasseler, $C k$; coarse Komet, Mk: medium Komet, SCb; super Coarse Brasseler, SCk; super coarse Komet. (JMP/Pro Ver13, SAS Inst. Inc., Cary, NC). 


\begin{tabular}{|c|c|c|c|c|c|c|}
\hline Bur & Source & DF & $\begin{array}{c}\text { Sum of } \\
\text { Squares }\end{array}$ & Mean Square & F Ratio & Prob > F \\
\hline Coarse & Study & 1 & 0.604654 & 0.60465 & 0.4818 & 0.4965 \\
(Brasseler) & Error & 18 & 22.588175 & 1.25490 & & \\
& C. Total & 19 & 23.192829 & & & \\
\hline Coarse & Study & 1 & 4.295486 & 4.29549 & 2.7092 & 0.1171 \\
(Komet) & Error & 18 & 28.539594 & 1.58553 & & \\
& C. Total & 19 & 32.835080 & & & \\
\hline Medium & Study & 1 & 0.947429 & 0.947429 & 1.4583 & 0.2428 \\
(Komet) & Error & 18 & 11.694143 & 0.649675 & & \\
& C. Total & 19 & 12.641572 & & & \\
\hline Super & Study & 1 & 1.600517 & 1.60052 & 1.5023 & 0.2361 \\
Coarse & Error & 18 & 19.176853 & 1.06538 & & \\
(Brasseler) & C. Total & 19 & 20.777371 & & & \\
\hline Super & Study & 1 & 0.037379 & 0.03738 & 0.0255 & 0.8750 \\
Coarse & Error & 18 & 26.434652 & 1.46859 & & \\
(Komet) & C. Total & 19 & 26.472031 & & & \\
\hline
\end{tabular}

Table 7. Analysis of variance between tapered and parallel shaped burs, study has two levels Alexander's and Alenezi's. 


\section{Discussion}

This study evaluated the cutting efficiency of diamond burs on sintered 3Y-TZP as measured by rate. According to the results obtained from this study, the first null hypothesis that the bur coarseness will not have an effect on cutting efficiency within 5 minutes was rejected as there was a significant difference found among the burs of different coarseness level. However, the second null hypothesis that the shape of the bur will not have an effect on cutting efficiency within 5 minutes was accepted as there was no significant difference found between tapered and parallel burs. The third null hypothesis that the prolonged cutting procedure will not have an effect on cutting efficiency among the burs in the study within 5 minutes was rejected. All the burs in the current study showed a significant decline in their cutting rate after the first 100 seconds.

At the end of each run, the mean of the depth cuts showed that bur E, G, and D performed the best throughout the 5 minutes as recorded by their average depths of $4.35 \mathrm{~mm}, 3.96 \mathrm{~mm}$, and $3.90 \mathrm{~mm}$, respectively. Bur E (6858) is a coarse diamond bur with an average diamond particle size of $151 \mu \mathrm{m}$. Bur G (6856DC) had an average diamond particle size of $151 \mu \mathrm{m}$ and had been marketed to be used for cutting zirconia crowns. Bur D (5856) was a super coarse diamond with an averaged diamond particle size of $181 \mu \mathrm{m}$. No significant difference in cutting rate were detected for these three burs. The rates of cut in 5 minutes for burs E, D and G were 0.0145, 0.0132 and $0.0130 \mathrm{~mm} / \mathrm{sec}$ respectively. The cutting depth of these three burs was superior to the other burs used in this study. Also, these three burs had the highest diamond particle size of the burs examined. The results showed that particle size of $151 \mu \mathrm{m}$ or greater demonstrated a significant influence in the cutting rate on 3 Y-TZP. It should be noted, with the exception of bur (G) which is marketed for ceramic removal, that manufacturing seems to play a critical role in the efficiency of the diamond bur against zirconia. 
When examining bur $(\mathrm{F})$, which is a medium grit diamond bur with an average diamond particle size of $107 \mu \mathrm{m}$, the cutting efficiency rate was $0.0095 \mathrm{~mm} / \mathrm{sec}$ and was not significantly higher than that of bur (A) or bur (B) which had a rate 0.0086 and $0.0084 \mathrm{~mm} / \mathrm{sec}$ respectively. Bur (A) is a super coarse diamond bur with an average particle size of $150 \mu \mathrm{m}$ and bur B is marketed as a coarse diamond bur with an averaged diamond particle size of $125 \mu \mathrm{m}$. However, statistical analysis showed that bur (F) was still significantly superior to bur (C) which is also a medium diamond bur but with a smaller average particle size of $100 \mu \mathrm{m}$.

Even though our study was focused on tapered diamond burs, the effect of bur shape on cutting rate would make for an interesting comparison. To evaluate this a comparison between the results obtained from this study and the results obtained from Alexander's study ${ }^{74}$ demonstrated that bur geometry has no effect on rate. Each bur in this study was compared to its corresponding bur from the previous study (Fig.7). One-way ANOVA showed that there was no significant difference between the tapered and the parallel burs with regards to zirconia cutting rate.

There was no significant differences found between burs A, B, and C in cutting rate of 3Y-TZP even though they possessed different diamond grit sizes. Interestingly, these burs were also produced by the same manufacturer. A similar finding was found by Blue $e t a l^{75}$ where Super Coarse and medium diamond burs, from the same manufacturer as burs A, B, and C, were shown not to be significantly different in cutting zirconia abutments. What is interesting though, is that bur $\mathrm{G}$ which is also made by the same manufacturer and marketed under the trade name DuraCut was among the most efficient burs in the study. Bur $\mathrm{G}$ has a particle size of $151 \mu \mathrm{m}$ which is very close to Bur A $(150 \mu \mathrm{m})$. To determine the possible cause of Bur G's significantly greater rate over bur A we evaluated the possible manufacturing difference between these burs. Carter and Norton have mentioned that for the quality of diamond burs, selecting a manufacturer is more essential than selecting the shape and design. ${ }^{38}$ They showed that processing the diamond particles and bonding them to the shank is of great importance. This may explain why bur (G) demonstrated being one of the fastest burs in this study as the manufacturer claims that an improved bonding process was used in the fabrication of the bur. This might suggest that processing of the bur is the main indicator of its efficiency. 
Bur $(\mathrm{G})$ manufacturer claimed that the use of Chromium Nitride coating in processing the diamond bur improved the bonding of the diamond particles to the bur shank. One important factor of this weak bond is the great difference in the CTE between diamond and the metal shank. ${ }^{76}$ Chromium Nitride can be used as a an interlayer for diamond deposition on steel substrates. An improved adhesion to the metal can be obtained using this method. The introduction of this bonding method was in 1995 when a group at the Solid State Institute in Israel suggested a $10 \mu \mathrm{m}$ thick film between the diamond particles and the substrate. The adhesion strength was reported to be up to $1000 \mathrm{~N} .{ }^{77}$ However, no current literature was found that discusses the implementation of chromium nitride into diamond dental burs. Nevertheless, from the results of this study, it would appear that the coating resulted in the higher efficiency of the bur $(G)$.

All the diamond burs in the study showed general decline in cutting rate through the 5 minutes. The decline in cutting rate was statistically significant between the Periods. Cutting rate of Period 1 was significantly higher in all the burs than Periods 2 and 3. The decline was continuous throughout Periods 2 and 3 but there was no significant difference between the two Periods. It can be determined that when using the burs in this study, there is always a significant decline in cutting rate after 100 seconds when cutting 3Y-TZP. This decline in cutting efficiency comes in agreement with many other studies that have shown a decline in cutting efficiency of diamond burs ${ }^{63 ; 67 ; 68 ; 71 ; 72}$. Siegel examined diamond burs with SEM after one minute of cutting ceramics and found that the debris almost totally clogged the surface of the bur which reduced the cutting efficiency of the burs. ${ }^{67}$

In the first period, a major difference was noticed as Bur (A) performed significantly better in Period 1 than Bur (C). Later, the difference between $(A)$ and $(C)$ became insignificant through the 5 minutes. For the top performers, (E), (G) and (D) a slightly different pattern was noticed between the burs as Bur $(\mathrm{G})$ was found to be most efficient bur in 100 seconds. However, there was no significant difference found between these three burs. 
The present study suffered from several limitations compared to 3Y-TZP used in the clinical setting. One of limitations of this study was the absence of aging effects on the zirconia specimens. Most of the in vitro studies addressing zirconia restorations are usually made with $3 \mathrm{Y}$-TZP with nearly $100 \%$ of the zirconia in the tetragonal phase ${ }^{46}$. Cyclic fatigue loading, thermocycling, and low temperature degradation may contribute to structural changes in the zirconia which may aid in weakening the material. Low temperature degradation (LTD) is an unintentional change to the monoclinic phase that is induced by hydrothermal aging in the humid oral environment. This unintentional change occurs as the energy barrier for tetragonal $\rightarrow$ monoclinic phase transformation is reduced due to zirconia incorporating water molecules into the lattice. The transformation spreads on the surface and penetrates through the depth of the material. This slow process results in a significant reduction in the material strength, toughness and density. ${ }^{78}$ Kohorst $^{79}$ tested the effect of aging on $3 \mathrm{Y}-\mathrm{TZP}$ ceramic by hydrothermally aging the specimens in steam at $134^{\circ} \mathrm{C}$ for different periods and using $\mathrm{x}$-ray diffraction and scanning electron microscopy to evaluate the phase transformation and the depth of the transformation zone. The X-ray diffraction has indicated a significant increase in the monoclinic phase content. This change resulted in the flexural strength of the 3Y-TZP to drop from 1750 to $1169 \mathrm{MPa}$. The effect of low temperature degradation might influence the cutting efficiency of diamond burs. Thus, as we did not age our $3 \mathrm{Y}$-TZP substrate it is possible that we were measuring the cutting rate of burs against a material stronger than would be found in the clinical setting.

Another potential limitation which may effect cutting efficiency of diamond burs is the coolant flow rate from the handpiece. In the United States, 15 to $20 \mathrm{ml} / \mathrm{min}$ is a typical coolant flow rate for high speed handpieces. ${ }^{60}$ Increasing the amount of coolant spray water at the bur/cut surface markedly affects the cutting rate of the handpiece as it has been reported that the cutting rate was increased with coolant rates over the range of $15-44 \mathrm{ml} / \mathrm{min} .{ }^{80}$ Even though the mechanism is still not well understood, some authors have speculated that higher rate could minimize the accumulation of the debris on the bur which in return will keep the cutting efficiency high for a longer period of time. ${ }^{81}$ Presence of fluids providing a low coefficient of friction was proposed as an alternative to aid cutting efficiency. In a study that evaluated addition of mouthwash to the coolant water at different concentrations found that 1:5 and 1:10 mouthwash to water ratio increased the cutting rate of diamond burs more than $130 \% .{ }^{82}$ These 
previous studies used machinable ceramic (Macor, Corning Inc.) to simulate enamel. Further studies using $3 \mathrm{Y}$-TZP with different coolant flow rates and different fluids mixtures might provide better understandings about the effect of these two variables in the cutting efficiency of diamond burs. In our study though we used a fixed coolant flow rate of $16 \mathrm{~mL} / \mathrm{min}$ to standardize the effect but in the clinical setting an operator can set that rate to what is most effective for cutting rate and patient comfort.

Another limitation of the study is the absence of surface grinding and sandblasting effects on the zirconia specimens. Grinding of the zirconia during lab fabrication or at the insertion appointments could introduce deep surface flaws that can concentrate the stress and weaken the restoration. Disturbing the matrix layer that strengthens zirconia restorations could weaken the prosthesis significantly if the grinding was extensive. Sandblasting the restoration is a common practice to improve bonding that could also the mechanical properties of the material. Kosmac et $a l{ }^{83}$ have evaluated the effects of grinding and sandblasting on flexural strength of $3 \mathrm{Y}-\mathrm{TZP}$. The authors found that sandblasting alone could increase the strength of $3 \mathrm{Y}$-TZP. This finding was explained by possible ring cracks being developed as a result of sandblasting that do not extend into the bulk of the material. However, grinding was found to increase the effective critical defect size through generating surface cracks that was observed in SEM examinations. Dry grinding was found to have more damaging to the flexural strength than wet grinding. The authors noticed that strength of 3Y-TZP went down from $1021 \mathrm{MPa}$, which was for untreated surface, to $543 \mathrm{MPa}$ after dry grinding, which was almost half the initial strength. In a similar fashion, wet grinding reduced the strength to $642 \mathrm{MPa}$. However, the authors found that dry grinding followed by sandblasting increased the strength of 3Y-TZP. SEM evaluation explained this increase by the ability of sandblasting to remove the surface defect and reducing the defect size. It was observed that sandblasting eroded the surface from the cracks that was started from dry grinding. As our $3 \mathrm{Y}$-TZP blocks received no additional surface treatments beyond sintering, it is possible that the material we used did not demonstrate the same imperfections as found in clinical zirconia.

Even given this studies perceived limitations, it is believed that this study has provided valuable information which may improve clinical practice. While our 3Y-TZP blocks may not 
fully simulate the clinical setting, the standardization of the cutting surface has allowed for a direct comparison of bur cutting effectiveness. This study demonstrates that well manufactured bur with a diamond particle size of greater than $151 \mu \mathrm{m}$ can rapidly cut 3Y-TZP zirconia in the first $100 \mathrm{sec}$ of use regardless of bur geometry. 


\section{Chapter V: Summary and Conclusion}

\section{Summary}

There is a recent increase of use of zirconia restorations in dentistry. $3 \mathrm{Y}$-TZP is the most widely used material for zirconia restorations. Failure of zirconia restorations due to caries or severe chipping will require removal and replacement of the restoration. The cutting of zirconia restorations is a time-consuming procedure due to zirconia's high hardness value. Diamond burs could differ in cutting efficiency of dental zirconia as measured by cutting rate. This study examined seven different burs on their cutting rate against $3 \mathrm{Y}$-TZP, and demonstrated that well manufactured burs with a diamond grit greater than $150 \mu \mathrm{m}$ were the fastest. These results were also compared to a previous study with same grit size but different shape burs, revealing that bur geometry did not affect cutting rate. The data obtained from this study can be implemented in everyday practice to increase time-efficiency and minimize cost of removing zirconia restorations.

\section{Conclusion}

1) Diamond burs with average grit size of $\geq 151 \mu \mathrm{m}$ were the most efficient bur types in cutting sintered $3 \mathrm{Y}$-TZP in 5 minutes and in the first 100 seconds when measured by rate of cutting.

2) Manufacturing process of the diamond burs apparently plays a great factor in determining the efficiency of the bur.

3) Rate of cutting of all diamond burs was reduced significantly after 100 seconds.

4) No difference was found between tapered and parallel sided diamond burs in cutting sintered $3 \mathrm{Y}-\mathrm{TZP}$ in 5 minutes.

5) Cutting efficiency of diamond burs on $3 \mathrm{Y}-\mathrm{TZP}$ is partially dependent on the coarseness of the bur. 


\section{References}

1 CONNY, D. J. et al. Changes of attitude in fixed prosthodontic patients. J Prosthet Dent, v. 53, n. 4, p. 451-4, Apr 1985. ISSN 0022-3913. Disponível em: <

https://www.ncbi.nlm.nih.gov/pubmed/3858507 >.

PRÖBSTER, L. et al. In vitro evaluation of a glass-ceramic restorative material. J Oral Rehabil, v. 24, n. 9, p. 636-45, Sep 1997. ISSN 0305-182X. Disponível em: < https://www.ncbi.nlm.nih.gov/pubmed/9357743 >.

ANUSAVICE, K. J.; PHILLIPS, R. W. Phillips' science of dental materials. 11th. St. Louis, Mo.: Saunders, 2003. xxv, 805 p. ISBN 0721693873.

THOLEY, M.; STEPHAN, M. Haftverbund mechanismen in dentalen Schichtsystemen: Quintessenz Zahntech. 24: 299-307 p. 2008.

MASSIRONI, D.; PASCETTA, R.; ROMEO, G. Precision in dental esthetics : clinical and laboratory procedures. Milan ; London: Quintessenza, 2007.

LARSSON, C.; WENNERBERG, A. The clinical success of zirconia-based crowns: a systematic review. Int J Prosthodont, v. 27, n. 1, p. 33-43, 2014 Jan-Feb 2014. ISSN 0893-2174. Disponível em: < https://www.ncbi.nlm.nih.gov/pubmed/24392475 >.

MCLEAN, J. W. Evolution of dental ceramics in the twentieth century. J Prosthet Dent, v. 85, n. 1, p. 61-6, Jan 2001. ISSN 0022-3913. Disponível em: < https://www.ncbi.nlm.nih.gov/pubmed/11174680 >.

LE, M.; PAPIA, E.; LARSSON, C. The clinical success of tooth- and implant-supported zirconia-based fixed dental prostheses. A systematic review. J Oral Rehabil, v. 42, n. 6, p. 467-80, Jun 2015. ISSN 1365-2842. Disponível em: < https://www.ncbi.nlm.nih.gov/pubmed/25580846 >.

CHRISTENSEN, G. J. The all-ceramic restoration dilemma: where are we? J Am Dent Assoc, v. 142, n. 6, p. 668-71, Jun 2011. ISSN 1943-4723. Disponível em: < https://www.ncbi.nlm.nih.gov/pubmed/21628690 >. 
SCHMITT, J. et al. Zirconia posterior fixed partial dentures: 5-year clinical results of a prospective clinical trial. Int J Prosthodont, v. 25, n. 6, p. 585-9, 2012 Nov-Dec 2012. ISSN 0893-2174. Disponível em: < https://www.ncbi.nlm.nih.gov/pubmed/23101038 >.

The glossary of prosthodontic terms. J Prosthet Dent, v. 9th edition, 2017.

LAND, C. H. A New System of Restoring Badly Decayed Teeth by Means of an Enameled Metallic Coating: Independent Pratt. 7: 407-409 p. 1886.

HOBO, S.; SHILLINGBURG, H. T. Porcelain fused to metal: tooth preparation and coping design. J Prosthet Dent, v. 30, n. 1, p. 28-36, Jul 1973. ISSN 0022-3913. Disponível em: < https://www.ncbi.nlm.nih.gov/pubmed/4575207 >.

BRECKER, S. C. The porcelain jacket crown, a new approach in the preparation. Dent Items Interest, v. 71, n. 2, p. 122-33, Feb 1949. ISSN 0096-0195. Disponível em: < https://www.ncbi.nlm.nih.gov/pubmed/18110482 >.

WEINSTEIN M, W. A. Porcelain-Covered Metal-Reinforced Teeth September 11, 1962.

NELSON, S. J. A. Wheeler's dental anatomy, physiology, and occlusion. $10^{\text {th }}$ edition. St. Louis, Missouri. 2015.

KELLY, J. R.; BENETTI, P. Ceramic materials in dentistry: historical evolution and current practice. Aust Dent J, v. 56 Suppl 1, p. 84-96, Jun 2011. ISSN 1834-7819. Disponível em: $<$ https://www.ncbi.nlm.nih.gov/pubmed/21564119 $>$.

LAND, C. H. A New System of Restoring Badly Decayed Teeth by Means of an Enameled Metallic Coating: Independent Pratt. 7: 407-409 p. 1886.

ROSENSTIEL, S. F.; LAND, M. F.; FUJIMOTO, J. Contemporary fixed prosthodontics. 4th ed. St. Louis, Mo.: Mosby Elsevier, 2006.

KELLY, J. R. Dental ceramics: current thinking and trends. Dent Clin North Am, v. 48, n. 2, p. viii, 513-30, Apr 2004. ISSN 0011-8532. Disponível em: < https://www.ncbi.nlm.nih.gov/pubmed/15172614 >.

$J R, K$. Ceramic in restorative and prosthetic dentistry: Ann Rev Mater Sci. 27: 443-68 p. 1997.

DEANY, I. L. Recent advances in ceramics for dentistry. Crit Rev Oral Biol Med, v. 7, n. 2, p. 134-43, 1996. ISSN 1045-4411. Disponível em: < https://www.ncbi.nlm.nih.gov/pubmed/8875028 >. A, W. Vefahrenund Ofen zur Herstellung von Zahnersatzteilen 1987. 
MCLEAN, J. W.; HUGHES, T. H. The reinforcement of dental porcelain with ceramic oxides. Br Dent J, v. 119, n. 6, p. 251-67, Sep 1965. ISSN 0007-0610. Disponível em: < https://www.ncbi.nlm.nih.gov/pubmed/5212704 >.

MACCULLOCH, W. T. Advances in dental ceramics. Br Dent J, v. 124, n. 8, p. 361-5, Apr 1968. ISSN 0007-0610. Disponível em: < https://www.ncbi.nlm.nih.gov/pubmed/5239147 $>$.

DG, G. Tetrasilicic mica glass-ceramic method. US patent 3,732,087. 1973.

GROSSMAN, D. G. Cast glass ceramics. Dent Clin North Am, v. 29, n. 4, p. 725-39, Oct 1985. ISSN 0011-8532. Disponível em: < https://www.ncbi.nlm.nih.gov/pubmed/3908163 $>$.

RAUCH, A. et al. Clinical survival of chair-side generated monolithic lithium disilicate crowns:10-year results. Clin Oral Investig, Nov 2017. ISSN 1436-3771. Disponível em: < https://www.ncbi.nlm.nih.gov/pubmed/29103104 >.

ALBAKRY, M.; GUAZZATO, M.; SWAIN, M. V. Biaxial flexural strength, elastic moduli, and $\mathrm{X}$-ray diffraction characterization of three pressable all-ceramic materials. J Prosthet Dent, v. 89, n. 4, p. 374-80, Apr 2003. ISSN 0022-3913. Disponível em: < https://www.ncbi.nlm.nih.gov/pubmed/12690350 >.

ETMAN, M. K.; WOOLFORD, M. J. Three-year clinical evaluation of two ceramic crown systems: a preliminary study. J Prosthet Dent, v. 103, n. 2, p. 80-90, Feb 2010. ISSN 1097-6841. Disponível em: < https://www.ncbi.nlm.nih.gov/pubmed/20141812 >.

PIEGER, S.; SALMAN, A.; BIDRA, A. S. Clinical outcomes of lithium disilicate single crowns and partial fixed dental prostheses: a systematic review. J Prosthet Dent, v. 112, n. 1, p. 22-30, Jul 2014. ISSN 1097-6841. Disponível em: < https://www.ncbi.nlm.nih.gov/pubmed/24674802 >.

ANDERSSON, M.; ODÉN, A. A new all-ceramic crown. A dense-sintered, high-purity alumina coping with porcelain. Acta Odontol Scand, v. 51, n. 1, p. 59-64, Feb 1993. ISSN 0001-6357. Disponível em: < https://www.ncbi.nlm.nih.gov/pubmed/8451925 >.

RAIGRODSKI, A. J. Clinical and laboratory considerations for the use of CAD/CAM Y-TZPbased restorations. Pract Proced Aesthet Dent, v. 15, n. 6, p. 469-76; quiz 477, Jul 2003. ISSN 1534-6846. Disponível em: < https://www.ncbi.nlm.nih.gov/pubmed/13677838 >.

HEFFERNAN, M. J. et al. Relative translucency of six all-ceramic systems. Part I: core materials. J Prosthet Dent, v. 88, n. 1, p. 4-9, Jul 2002. ISSN 0022-3913. Disponível em: < https://www.ncbi.nlm.nih.gov/pubmed/12239472 >. 
HEFFERNAN, M. J. et al. Relative translucency of six all-ceramic systems. Part II: core and veneer materials. J Prosthet Dent, v. 88, n. 1, p. 10-5, Jul 2002. ISSN 0022-3913. Disponível em: < https://www.ncbi.nlm.nih.gov/pubmed/12239473 >.

DENRY, I.; KELLY, J. R. State of the art of zirconia for dental applications. Dent Mater, v. 24, n. 3, p. 299-307, Mar 2008. ISSN 0109-5641. Disponível em: < https://www.ncbi.nlm.nih.gov/pubmed/17659331 >.

CRC handbook of chemistry and physics. Boca Raton, FL: Chapman and Hall/CRCnetBASE: CD-ROMs p. 1999.

CARTER, C. B.; NORTON, M. G. Ceramic materials : science and engineering. New York: Springer, 2007. xxii, 716 p. ISBN 9780387462707 (hbk.) 0387462708 (hbk.). Disponível em: < Publisher description http://www.loc.gov/catdir/enhancements/fy0825/2006938045-d.html >. GARVIE, R. C.; HANNINK, R. H.; PASCOE, R. T. Ceramic steel?: Nature. 258: 703 p. 1975.

DENRY, I.; KELLY, J. R. Emerging ceramic-based materials for dentistry. J Dent Res, v. 93, n. 12, p. 1235-42, Dec 2014. ISSN 1544-0591. Disponível em: < https://www.ncbi.nlm.nih.gov/pubmed/25274751 >.

SHAHMIRI, R. et al. Optical properties of zirconia ceramics for esthetic dental restorations: A systematic review. J Prosthet Dent, v. 119, n. 1, p. 36-46, Jan 2018. ISSN 1097-6841. Disponível em: < https://www.ncbi.nlm.nih.gov/pubmed/28927925 >.

HEINTZE, S. D.; ROUSSON, V. Survival of zirconia- and metal-supported fixed dental prostheses: a systematic review. Int J Prosthodont, v. 23, n. 6, p. 493-502, 2010 Nov-Dec 2010. ISSN 0893-2174. Disponível em: < https://www.ncbi.nlm.nih.gov/pubmed/21209982 >.

CHRISTENSEN, R. P.; PLOEGER, B. J. A clinical comparison of zirconia, metal and alumina fixed-prosthesis frameworks veneered with layered or pressed ceramic: a three-year report. J Am Dent Assoc, v. 141, n. 11, p. 1317-29, Nov 2010. ISSN 1943-4723. Disponível em: < https://www.ncbi.nlm.nih.gov/pubmed/21037189 >.

SOLÁ-RUÍZ, M. F. et al. A prospective evaluation of zirconia anterior partial fixed dental prostheses: Clinical results after seven years. J Prosthet Dent, v. 113, n. 6, p. 578-84, Jun 2015. ISSN 1097-6841. Disponível em: < https://www.ncbi.nlm.nih.gov/pubmed/25794906 >. 
GHERLONE, E. et al. A 3 years retrospective study of survival for zirconia-based single crowns fabricated from intraoral digital impressions. J Dent, v. 42, n. 9, p. 1151-5, Sep 2014. ISSN 1879-176X. Disponível em: < https://www.ncbi.nlm.nih.gov/pubmed/24930869 >.

GALVÃO RIBEIRO, B. R. et al. Effect of surface treatments on repair with composite resin of a partially monoclinic phase transformed yttrium-stabilized tetragonal zirconia. J Prosthet Dent, v. 119, n. 2, p. 286-291, Feb 2018. ISSN 1097-6841. Disponível em: < https://www.ncbi.nlm.nih.gov/pubmed/28533011 >.

LOHBAUER, U. et al. Fracture of a veneered-ZrO 2 dental prosthesis from an inner thermal crack: Case Stud Eng Fail Anal. 2: 100-6 p. 2014.

THOLEY, M. J.; SWAIN, M. V.; THIEL, N. Thermal gradients and residual stresses in veneered Y-TZP frameworks. Dent Mater, v. 27, n. 11, p. 1102-10, Nov 2011. ISSN 18790097. Disponível em: < https://www.ncbi.nlm.nih.gov/pubmed/21907400 >.

IPS e.max ZirCAD Scientific Documentation. IVOCLAR-VIVADENT 2017.

GOODACRE, C. J.; CAMPAGNI, W. V.; AQUILINO, S. A. Tooth preparations for complete crowns: an art form based on scientific principles. J Prosthet Dent, v. 85, n. 4, p. 363-76, Apr 2001. ISSN 0022-3913. Disponível em: < https://www.ncbi.nlm.nih.gov/pubmed/11319534 >.

TARTAGLIA, G. M.; SIDOTI, E.; SFORZA, C. Seven-year prospective clinical study on zirconia-based single crowns and fixed dental prostheses. Clin Oral Investig, v. 19, n. 5, p. 1137-45, Jun 2015. ISSN 1436-3771. Disponível em: < https://www.ncbi.nlm.nih.gov/pubmed/25304166 >.

CONRAD, H. J.; SEONG, W. J.; PESUN, I. J. Current ceramic materials and systems with clinical recommendations: a systematic review. J Prosthet Dent, v. 98, n. 5, p. 389-404, Nov 2007. ISSN 0022-3913. Disponível em: < https://www.ncbi.nlm.nih.gov/pubmed/18021828 >.

HERMAN, G. L. Bucco-lingual "dimple" technique for removing full-crown and cast-metal restorations. N Y State Dent J, v. 77, n. 1, p. 17-9, Jan 2011. ISSN 0028-7571. Disponível em: < https://www.ncbi.nlm.nih.gov/pubmed/21417160 >.

TAK, O. et al. The effect of transmitted Er:YAG laser energy through a dental ceramic on different types of resin cements. Lasers Surg Med, Jul 2015. ISSN 1096-9101. Disponível em: < https://www.ncbi.nlm.nih.gov/pubmed/26154977 >. 
RECHMANN, P. et al. Laser all-ceramic crown removal-a laboratory proof-of-principle study-phase 1 material characteristics. Lasers Surg Med, v. 46, n. 8, p. 628-35, Oct 2014. ISSN 1096-9101. Disponível em: < https://www.ncbi.nlm.nih.gov/pubmed/25125132 >.

RECHMANN, P. et al. Laser all-ceramic crown removal-a laboratory proof-of-principle study-phase 2 crown debonding time. Lasers Surg Med, v. 46, n. 8, p. 636-43, Oct 2014. ISSN 1096-9101. Disponível em: < https://www.ncbi.nlm.nih.gov/pubmed/25125242 >.

ORGANIZATION, I. S. ISO 7711-3:Dentistry - Diamond Rotary instruments. $\underline{3}$ : Grit sizes, designation and colour code 2004.

NAYLOR, W. P.; BEATTY, M. W. Materials and techniques in fixed prosthodontics. Dent Clin North Am, v. 36, n. 3, p. 665-92, Jul 1992. ISSN 0011-8532. Disponível em: < https://www.ncbi.nlm.nih.gov/pubmed/1327885 >.

NORLING, B.; STANFORD, J. Evaluating performance of dental rotary cutting instruments. The Cutting Edge: Interfacial Dynamics of Cutting and Grinding. WELFARE, U. D. O. H. E. A. 1976.

VON FRAUNHOFER, J. A.; GIVENS, C. D.; OVERMYER, T. J. Lubricating coolants for highspeed dental handpieces. J Am Dent Assoc, v. 119, n. 2, p. 291-5, Aug 1989. ISSN 00028177. Disponível em: < https://www.ncbi.nlm.nih.gov/pubmed/2549111 >.

SEMMELMAN, J.; KULP, P.; LR, K. Cutting studies at air-turbine speeds: J Dent Res. 40(3): 404-10 p. 1961.

WATANABE, L.; SOELBERG, K.; PEIZNER, R. Diamond stones. In: Reports from product evaluation laboratory. Newtown, PA, p.17-24. 1987

SIEGEL, S. C.; VON FRAUNHOFER, J. A. Cutting efficiency of three diamond bur grit sizes. J Am Dent Assoc, v. 131, n. 12, p. 1706-10, Dec 2000. ISSN 0002-8177. Disponível em: < https://www.ncbi.nlm.nih.gov/pubmed/11143734 >.

OTTL, P.; LAUER, H. C. Temperature response in the pulpal chamber during ultrahighspeed tooth preparation with diamond burs of different grit. J Prosthet Dent, v. 80, n. 1, p. 12-9, Jul 1998. ISSN 0022-3913. Disponível em: < https://www.ncbi.nlm.nih.gov/pubmed/9656172 >. MCGRATH, K. A.; TRAVERS, B. World of invention. 2nd. Detroit: Gale, 1999.

CHOI, C.; DRISCOLL, C. F.; ROMBERG, E. Comparison of cutting efficiencies between electric and air-turbine dental handpieces. J Prosthet Dent, v. 103, n. 2, p. 101-7, Feb 2010. ISSN 1097-6841. Disponível em: < https://www.ncbi.nlm.nih.gov/pubmed/20141814 >. 
SIEGEL, S. C.; VON FRAUNHOFER, J. A. Assessing the cutting efficiency of dental diamond burs. J Am Dent Assoc, v. 127, n. 6, p. 763-72, Jun 1996. ISSN 0002-8177. Disponível em: $<$ https://www.ncbi.nlm.nih.gov/pubmed/8708278 $>$.

SIEGEL, S. C.; VON FRAUNHOFER, J. A.. Dental cutting with diamond burs: heavy-handed or light-touch? J Prosthodont, v. 8, n. 1, p. 3-9, Mar 1999. ISSN 1059-941X. Disponível em: < https://www.ncbi.nlm.nih.gov/pubmed/10356549 >.

ROTELLA, M. et al. Performance of single-use and multiuse diamond rotary cutting instruments with turbine and electric handpieces. J Prosthet Dent, v. 111, n. 1, p. 56-63, Jan 2014. ISSN 1097-6841. Disponível em: <

https://www.ncbi.nlm.nih.gov/pubmed/24246370 >.

NAKAMURA, K. et al. Cutting efficiency of diamond burs operated with electric highspeed dental handpiece on zirconia. Eur J Oral Sci, Aug 2015. ISSN 1600-0722.

Disponível em: < https://www.ncbi.nlm.nih.gov/pubmed/26315542 >.

YIN, L.; JAHANMIR, S.; IVES, L. K. Abrasive machining of porcelain and zirconia with a dental handpiece: Wear. 255: 975-989 p. 2003.

YIN, L. et al. Abrasive Machining of Glass-Infiltrated Alumina with Diamond burs: Machining Science and Technology. 5(1): 43-61 p. 2001.

CARTER, B. C.; NORTON, G. M. Ceramic Materials Science and Engineering.

ALEXANDER, S. A. Diamond Burs Cutting Efficiency of Dental Zirconia. 2016. Dentistry, West Virginia University, Morgantown,WV.

BLUE, D. S. et al. Effects of bur abrasive particle size and abutment composition on preparation of ceramic implant abutments. J Prosthet Dent, v. 90, n. 3, p. 247-54, Sep 2003. ISSN 0022-3913. Disponível em: < https://www.ncbi.nlm.nih.gov/pubmed/12942058 >.

GLOZMAN, O.; HOFFMAN, A. Adhesion improvement of diamond films on steel substrate using chromium nitride interlayers: Diamond and related materials. 6: 796801 p. 1997.

FAYER, A.; GLOZMAN, O.; HOFFMAN, A. Deposition of continuous and well adhering diamond films on steel: Appl. Phys. Lett. 67: 2299 p. 1995.

BORCHERS, L. et al. Influence of hydrothermal and mechanical conditions on the strength of zirconia. Acta Biomater, v. 6, n. 12, p. 4547-52, Dec 2010. ISSN 1878-7568. Disponível em: < https://www.ncbi.nlm.nih.gov/pubmed/20656076 >. 
KOHORST, P. et al. Low-temperature degradation of different zirconia ceramics for dental applications. Acta Biomater, v. 8, n. 3, p. 1213-20, Mar 2012. ISSN 1878-7568. Disponível em: < https://www.ncbi.nlm.nih.gov/pubmed/22138551 >. VON FRAUNHOFER, J. A.; SIEGEL, S. C.; FELDMAN, S. Handpiece coolant flow rates and dental cutting. Oper Dent, v. 25, n. 6, p. 544-8, 2000 Nov-Dec 2000. ISSN 0361-7734. Disponível em: < https://www.ncbi.nlm.nih.gov/pubmed/11203868 >.

YIN, L.; IVES, L. L.; JAHANMIR, S. Effects of Fluids on the Simulated Clinical Dental Machining of a Glass Ceramic: Journal of the American Ceramic Society. V87: 173-75 p. 2004.

VON FRAUNHOFER, J. A.; SIEGEL, S. C. Enhanced dental cutting through chemomechanical effects. J Am Dent Assoc, v. 131, n. 10, p. 1465-9, Oct 2000. ISSN 0002-8177. Disponível em: < https://www.ncbi.nlm.nih.gov/pubmed/11042986 >.

KOSMAC, $T$. et al. The effect of surface grinding and sandblasting on flexural strength and reliability of Y-TZP zirconia ceramic. Dent Mater, v. 15, n. 6, p. 426-33, Nov 1999. ISSN 0109-5641. Disponível em: < https://www.ncbi.nlm.nih.gov/pubmed/10863444 >. 


\section{Curriculum Vitae}

Dhari Alenezi, D.D.S.

682B Killarney dr, Unit\#3, Morgantown, WV 26505 |(304) 216-0507|

Dhari.alenezi@gmail.com

EDUCATION

West Virginia University, Morgantown, WV

[M.S. in Prosthodontics]- expected graduation May 2018 2015-Present

West Virginia University, Morgantown, WV

Doctor of Dental Surgery 2009-2013

Licensure

West Virginia Board of Dentistry 2013-Present

MEMBERSHIPS

American College of Prosthodontists

Academy of Osseointegration 